\title{
Infrastructure and Organization of Adult Intensive Care Units in Resource-Limited Settings
}

\author{
Alfred Papali, Neill K. J. Adhikari, Janet V. Diaz, \\ Arjen M. Dondorp, Martin W. Dünser, Shevin T. Jacob, \\ Jason Phua, Marc Romain, and Marcus J. Schultz
}

\subsection{Introduction}

Published guidelines regarding optimal infrastructure and organization of intensive care units (ICUs) are based on evidence primarily from resource-rich settings [1]. These guidelines may be less applicable to resource-limited settings [2]. ICUs

\footnotetext{
A. Papali

Division of Pulmonary and Critical Care Medicine, Atrium Health, Charlotte, NC, USA

Division of Pulmonary and Critical Care, Institute of Global Health, University of Maryland
} School of Medicine, Baltimore, MD, USA

N. K. J. Adhikari

Sunnybrook Health Sciences Centre, University of Toronto, Toronto, ON, Canada

J. V. Diaz

Pacific Medical Center, San Francisco, CA, USA

World Health Organization, Geneva, Switzerland

A. M. Dondorp

Faculty of Tropical Medicine, Mahidol University, Bangkok, Thailand

Academic Medical Center, University of Amsterdam, Amsterdam, The Netherlands

Nuffield Department of Clinical Medicine, Oxford Centre for Tropical Medicine and Global Health, University of Oxford, Oxford, UK

M. W. Dünser $(\bowtie)$

Department of Anesthesia and Intensive Care Medicine, Kepler University Hospital,

Johannes Kepler University Linz, Linz, Austria

S. T. Jacob

World Health Organization, Geneva, Switzerland

University of Washington School of Medicine, Seattle, WA, USA

Liverpool School of Tropical Medicine, Liverpool, UK 
J. Phua

National University Hospital, Singapore, Singapore

M. Romain

Hadassah-Hebrew University Medical Center, Jerusalem, Israel

M. J. Schultz

Faculty of Tropical Medicine, Mahidol University, Bangkok, Thailand

Department of Intensive Care, Academic Medical Center, Amsterdam, The Netherlands

Laboratory of Experimental Intensive Care and Anesthesiology (L.E.I.C.A),

Academic Medical Center, Amsterdam, The Netherlands

around the world differ in available resources, and our working group [2] and others [1] have different definitions what an ICU entails. In this chapter, we aim to answer seven questions basic prerequisites for quality intensive care in resource-limited settings: (1) Which healthcare professionals should provide care in ICUs in resourcelimited settings? (2) How should these healthcare professionals be trained? (3) How should electricity be supplied to ICUs in resource-limited settings? (4) How should oxygen be supplied to ICUs in resource-limited settings? (5) Which hygienic facilities are fundamental in ICUs in resource-limited settings? (6) Which technical equipment should be available in ICUs in resource-limited settings? (7) Which quality measures to improve care should be implemented in ICUs in resourcelimited settings? We provide a series of simple, pragmatic recommendations for optimizing ICU infrastructure and organization in resource-limited settings, with a focus on adult ICUs (Table 3.1). Understanding the great variability of technical, material, and human resources within and between these environments, each institution must determine the utility of implementing these recommendations based on local capabilities.

\subsection{Staffing}

In resource rich settings, intensive care medicine has evolved into a multidisciplinary and team-based approach. Involvement of ICU physicians and other healthcare professionals results in better outcomes and reduces costs of care [3, 4]. Postgraduate training in the specialty of intensive care medicine is becoming more commonplace for ICU physicians, ICU nurses, and even allied healthcare professionals in most high-income countries [5, 6]; training in intensive care medicine is commonly available for physicians from different medical specialties. Most training programs last at least 1 year and end with a national or international examination [6]. Accreditation and certification in different sub-specialties (e.g., neuro-intensive care) or examination techniques (e.g., echocardiography, lung ultrasound) can be achieved in some countries [6].

Studies in resource-rich settings show that the physician-staffing model in use affects outcomes of critically ill patients [7-9]. In comparison to a so-called open ICU model, in which physicians from outside the ICU remain directly responsible 
Table 3.1 Recommendations for ICU infrastructure and organization in resource-limited settings (with grading)

\begin{tabular}{|c|c|c|}
\hline 1 & Staffing & $\begin{array}{l}\text { We suggest that, if possible, ICUs use a closed-format model where physicians } \\
\text { specifically trained or experienced in intensive care medicine direct patient care } \\
\text { (2B). We further suggest that ICUs be staffed with nurses who are trained in } \\
\text { intensive care nursing (2C). Wherever available, allied healthcare professionals } \\
\text { (e.g., pharmacists) should be part of an ICU team (UG). Currently, no } \\
\text { recommendation on ICU telemedicine in resource-limited settings can be made }\end{array}$ \\
\hline 2 & Training & $\begin{array}{l}\text { We suggest that all healthcare professionals working in ICUs be specifically } \\
\text { trained in the care of the critically ill patient (2C). Unless national or regional } \\
\text { specialty training programs in intensive care medicine are available, we } \\
\text { suggest that training of ICU physicians, nurses, and allied healthcare } \\
\text { professionals occurs through longitudinal, multimodal programs coordinated } \\
\text { by partnerships between Ministries of Health, national and international } \\
\text { professional societies, nongovernmental organizations, as well as institutions } \\
\text { with well-established programs in ICU training (2D). We recommend that such } \\
\text { ICU training programs adhere to validated, international standards of intensive } \\
\text { care medicine, but that they be adapted to local needs and resources (1C) }\end{array}$ \\
\hline 3 & Electricity & $\begin{array}{l}\text { A stable electricity supply is an essential infrastructural component of an ICU } \\
\text { (UG). We recommend that ICUs use voltage stabilizers in case voltage } \\
\text { fluctuations endanger the function of electrical medical equipment (1D). We } \\
\text { recommend that adequate backup electrical sources be available to bridge } \\
\text { power cuts (1C). We suggest that these backup electrical sources take over } \\
\text { electricity supply automatically allowing for (near) continuous functioning of } \\
\text { life-sustaining medical equipment (2D). We recommend that ICUs with no } \\
\text { adequate backup electrical source have protocols in place guiding ICU staff } \\
\text { how to bridge life-sustaining therapies during power cuts (1D) }\end{array}$ \\
\hline 4 & Oxygen & $\begin{array}{l}\text { Oxygen therapy is an essential provision for critically ill patients, and an } \\
\text { adequate oxygen supply is a crucial infrastructural component of an ICU } \\
\text { (UG). We recommend that ICUs choose the type of oxygen supply } \\
\text { (concentrators, cylinders, centralized system) based on site-specific conditions } \\
\text { and requirements (1B). We suggest that, if feasible, oxygen be supplied by } \\
\text { centralized, piped systems to ICUs when mechanical ventilators are used (2D) }\end{array}$ \\
\hline 5 & Hygiene & $\begin{array}{l}\text { We recommend that ICUs have available an adequate number of and easily } \\
\text { accessible facilities for handwashing/hand hygiene (1A). We recommend hand } \\
\text { hygiene after each patient contact with an alcohol-based solution (1A). } \\
\text { Exception are hand hygiene in the context of Ebola virus disease requiring } \\
\text { chlorine-based solutions (1C) and Clostridium difficile requiring water and } \\
\text { soap. In case alcohol-based solutions are unavailable, we recommend using } \\
\text { soap and water for handwashing (1A). Alcohol hand rub solutions may be } \\
\text { produced locally and carried in small bottles by each healthcare worker (UG). } \\
\text { We recommend that non-sterile, clean examination gloves for self-protection } \\
\text { of medical staff be available (1C). Importantly, gloved hands can equally } \\
\text { transmit infectious pathogens; use of gloves does not replace the need for } \\
\text { subsequent hand hygiene (UG). We recommend the availability of masks, } \\
\text { caps, sterile gowns, sterile drapes, and sterile gloves for invasive procedures, } \\
\text { such as insertion of central venous catheters (1A). We recommend that ICUs } \\
\text { and hospitals in areas where highly contagious infectious diseases (e.g., } \\
\text { tuberculosis, Ebola virus disease) are endemic have rapid access to adequate } \\
\text { quantities of personal protective equipment as recommended by the World } \\
\text { Health Organization and the Centers for Disease Control and Prevention (1C). } \\
\text { We suggest that hospitals develop individual policies and procedures for reuse } \\
\text { of disposable personal protective and other medical equipment (2C). When } \\
\text { ICUs are renovated or newly built, we suggest compliance with national and } \\
\text { international best-practice recommendations on ICU architectural design (2D) }\end{array}$ \\
\hline
\end{tabular}


Table 3.1 (continued)

\begin{tabular}{l|l|l}
\hline 6 & Equipment & $\begin{array}{l}\text { Acquisition of technical equipment should be guided by local availability and } \\
\text { feasibility of routine maintenance (UG). We recommend basic vital signs } \\
\text { monitors (including electrocardiogram, respiratory rate, oscillometric blood } \\
\text { pressure, and pulse oximetry) available for each ICU bed (1C). We } \\
\text { recommend that ICUs have one or more mechanical ventilators available } \\
\text { (1C). These mechanical ventilators should also deliver noninvasive ventilatory } \\
\text { modes, measure tidal volume and airway pressures, and support oxygen } \\
\text { delivery (1B). We suggest that ICUs providing invasive ventilatory support } \\
\text { have the ability to measure end-tidal carbon dioxide (2C) and to perform } \\
\text { blood gas analysis (2C). We recommend that ICUs have point-of-care } \\
\text { capabilities for measuring blood glucose (e.g., glucometers) (1B). We } \\
\text { recommend that ICUs have capabilities for measuring blood lactate levels } \\
\text { (1B). We suggest that ICUs have available point-of-care ultrasound devices } \\
\text { (2C) and that key clinical staff undergo formal ultrasound training (2C) }\end{array}$ \\
\hline 7 & $\begin{array}{l}\text { We recommend maintaining patient records and ICU documentation in } \\
\text { accordance with national regulations and requirements (1D). We suggest that } \\
\text { ICUs develop locally applicable bundles, protocols, and checklists to improve } \\
\text { quality of care (2C). We suggest that ICUs systematically collect quality and } \\
\text { performance indicators and participate in national/international benchmarking } \\
\text { projects (2C) }\end{array}$ \\
\hline
\end{tabular}

Abbreviations: $I C U$ intensive care unit, $U G$ ungraded

for the care of their patients, a so-called closed ICU model, in which one or more physicians, usually trained in intensive care medicine, and exclusively based within the ICU, become responsible for the critically ill patients, results in lower mortality rates, shorter length of stay, and reduced costs of care [7].

Studies in resource-rich settings also show that the nurse-staffing model affects outcomes of critically ill patients [10]. More nurses available per ICU bed improves survival rates, particularly for patients at a high risk of dying [11], reduces postoperative [12] and infectious complications like ventilator-associated pneumonia [13], and prevents medication errors [14]. A higher nurse-to-patient ratio is also independently associated with a better compliance with, for example, sepsis care bundles [15]. Notably, a higher nurse-to-patient ratio prevents burnout of nurses [16]. Studies in resource-rich settings also suggest that the presence of allied healthcare professionals like pharmacists [17], respiratory or physical therapists [18], and dieticians [19] within a multidisciplinary ICU team improves patient outcomes [3]. Furthermore, proactive communications with infectious disease specialists or microbiologists favorably affect antibiotic use and costs [20].

Finally, so-called telemedicine in ICUs in resource-rich settings, mainly to solve the problem of physician shortages during nighttime hours and in some ICUs with low-intensity staffing [21], has been shown to improve early identification of patients who deteriorate [22] and increases the number of interventions [23], but the effect on ICU outcomes remains controversial [24] and costs of required technological infrastructure are high [25].

There is minimal evidence from resource-limited settings that ICU outcomes improve after changing from an "open ICU model" to a "closed ICU model." One 
before-after study from Thailand showed a $4 \%$ absolute mortality reduction (from 27.4 to $23.4 \%, p=0.03)$ and shortening of length of stay of 0.8 days $(-1.3$ to -0.25 , $p<0.01)$ in a surgical ICU [26]. The reduction in mortality was greatest in patients with a length of stay $>48 \mathrm{~h}(22.7$ vs. $13.9 \%, p<0.01)$. A prospective before-after study in a large university hospital in Turkey demonstrated a 4.5-fold reduction of in-hospital mortality after introduction of the "closed ICU model" [27]. The survival effects were most prominent in patients requiring mechanical ventilation. Postgraduate training programs in intensive care medicine for physicians have been established in selected resource-limited settings such as India [28], Ethiopia [29], Brazil [30], China [31], and South Africa [32], but the literature fails to report on outcome changes after its establishment.

No studies have been published from resource-limited settings evaluating patient outcomes related to nurse-to-patient ratios. Evidence from resource-limited settings confirms the benefits of including pharmacists into the multidisciplinary ICU team on patient outcomes [17]. Studies from China, Thailand, Jordan, Egypt, and Vietnam demonstrated consistent reductions in medication costs [33-35] and adverse events [36] after involvement of a pharmacist in daily ICU practice. No studies on the effects of including physicians from other backgrounds (e.g., infectious disease specialists) or allied healthcare professionals (e.g., psychologists, case managers, social workers, respiratory therapists, dieticians, or physical therapists) into ICU teams in resource-limited settings were identified by our search.

Data on implementation of telemedicine in resource-limited ICUs is minimal despite reports of successful implementation in areas with a scarcity of specialists [37]. Only one study, performed in India in patients with acute myocardial infarction, showed a reduction in mortality following implementation of telemedicine [38].

Despite the trends indicating that a "closed ICU model" improves patient outcomes in resource-limited ICUs, human resources are inconsistently available in most of these settings. The number of physicians per 1000 inhabitants is substantially lower in low- and middle- than high-income countries [39]. This leaves many hospitals in resource-limited areas with a critical shortage of physicians, particularly during off-hours, weekends, and holidays. From the authors' experience, in some hospitals, a physician is completely absent during nighttime. Patient care is then, for example, overseen by mid-level providers, such as clinical officers.

No systematic data on the availability of physicians specialized in intensive care medicine have been published for resource-limited settings. There also are no studies detailing the relevance of ICU training methods typically found in resource-rich settings amid the different cultural and disease pattern contexts of resource-limited settings. Despite the availability of specialty training programs in selected countries, regional data and the experience of the authors suggest that intensive care specialists are unavailable in many ICUs in resource-limited settings [40]. Some ICUs in sub-Saharan Africa are, for example, run and staffed by "anesthetic officers" (non-physicians with specific training in certain elements of anesthesia) in close cooperation with surgeons, internal medicine specialists, and pediatricians [41-44]. 
The number of nurses per 1000 inhabitants is substantially lower in low- and middle- than in high-income countries [45]. Consequently, the number of nursing staff is limited in many ICUs in resource-limited settings [46]. Limited availability of nursing staff in resource-limited ICUs naturally leads to low nurse-to-patient ratios of often 1:4 or higher, particularly during off-hours and weekends. It can be assumed that similar associations between nurse-to-patient ratios and outcomes exist in resource-limited and resource-rich settings. However, given the general shortage of nursing staff, especially those trained in intensive care nursing, it is highly questionable whether cutoff values for nurse-to-patient ratios established in resource-rich setting specific guidelines (e.g., 1:2) can be extrapolated to ICUs in resource-limited settings. Allied healthcare professionals, such as physiotherapists and dieticians, are usually unavailable in many, if not most, resource-limited ICUs [40]. If these healthcare professionals are available in the hospital or even the ICU, they are, in the experience of the authors, often not trained or experienced in caring for the critically ill patient. Accordingly, dedicated critical care pharmacists are uncommon in many resource-limited ICUs [47], and even if available, their presence during ICU rounds, where benefits are strongest [48], is limited [49]. In addition, high staff-related costs may strain or exceed tight budgets of hospitals and be another reason why a multidisciplinary ICU model appears less feasible in resourcelimited than in resource-rich settings. In the absence of dedicated ICU staff, family members often assume an important role in caring for the patient.

Increasing global Internet connectivity and the ubiquity of mobile phones could facilitate low-cost ICU telemedicine and translate to rapid and accessible ICU consultative services in some resource-limited settings [50]. However, related implementation and maintenance costs, unavailability of stable Internet coverage in many rural or remote areas, and questions of credentialing and accountability for out-ofcountry-based telemedicine providers remain ongoing challenges. Author experience suggests that telemedicine links between "sister hospitals," one in a resource-limited setting and one in a resource-rich setting, may provide meaningful collaboration and educational opportunities on both sides. Finally, we could not identify any safety considerations to the implementation of a multidisciplinary team approach in ICUs in resource-limited settings.

We suggest that, if possible, ICUs use a closed-format model where physicians specifically trained or experienced in intensive care medicine direct patient care (2B). We further suggest that ICUs be staffed with nurses who are trained in intensive care nursing (2C). Wherever available, allied healthcare professionals (e.g., pharmacists) should be part of an ICU team (ungraded). Currently, no recommendation on ICU telemedicine in resource-limited settings can be made.

\subsection{Training}

The care of the critically ill patient substantially differs from noncritically ill patients and thus requires specific training of all healthcare professionals involved due to the complex care requirements. High-performing ICUs are typically staffed with ICU 
physicians and nurses and allied health professionals who, in addition to general training, have pursued further training in intensive care. Regulatory bodies in these settings frequently consider specialty certification as a prerequisite to permanently work in an ICU. However, formal intensive care specialty training programs are rare or nonexistent in resource-limited settings. This lack of specialty education is likely to translate into limited knowledge about the pathophysiology and diagnostic and therapeutic management of critically ill patients [51]. It remains unclear how healthcare professionals working in ICUs in resource-limited settings, where no established regional or national specialty education programs in intensive care medicine exist, should be trained.

The majority of studies from resource-limited settings describe small-scale, focused training courses in individual institutions and pre- and post-course tests of knowledge. Four investigations, one in Ghana [52] and three in Sri Lanka [53-55], were about regional or national training programs for physicians, ICU nurses, and physical therapists. Dedicated courses in trauma and intensive care- and emergency medicine-related procedures improve knowledge in "best clinical practice" of healthcare professionals working in ICUs in resource-limited settings [56, 57]. Focused training programs that use well-established training models, such as the "Fundamental Critical Care Support" course, facilitated immediate knowledge gain, especially in junior clinicians or those with limited practical experience taking care of critically ill patients [57]. However, data on influences on patient care and longterm knowledge retention are limited. Intensive care-specific courses also demonstrated benefit in allied health professionals in resource-limited settings [55].

A national train-the-trainers program for critical care nursing in Sri Lanka was structured as seven educational blocks over a period of 18 months [53]. Using didactics, simulation, and small group learning, by 2014, this program trained 584 nurses and 29 faculty and allowed local trainers eventually to take command of course directorship. In Ghana, a countrywide continuing medical education course in acute trauma management was developed, and targeting general practitioners in rural hospitals showed significant knowledge retention and critical procedural skills improvement even 1 year after course completion [52].

In locations where institutional, regional, or national courses are unavailable, the use of mobile health technology to facilitate intensive care education and training is of great interest. A pilot study in Haiti showed that non-physician ultrasound learners, linked to ultrasound instructors in the United States via mobile phone video chat technology, can learn how to obtain clinically useful ultrasound images [58]. Validated e-learning methodologies are also in use to enhance critical care education and capacity in Cambodia, although specific outcomes have yet to be declared [59].

Among nearly all available studies from resource-limited settings, a universal theme is partnerships between an institution based in a resource-limited and one in a resource-rich setting. These partnerships, when successful, can evolve from simple facility-to-facility ventures [60] to more longitudinal, systems-based programs [61]. Whether approached vertically (institution-based) or horizontally (systemsbased), partnerships also permit local personnel in resource-limited settings to advance knowledge or develop specific skill sets while remaining in their setting. In 
many cases, the goal is for the resource-limited settings partner to administer the program independently. One successful example of such a horizontally integrated program is the East African Training Initiative, a pulmonary/critical care fellowship training program in Addis Ababa, Ethiopia [29]. In partnership with the Ethiopian Ministry of Health, international professional societies, nongovernmental organizations, and a consortium of universities in Europe and North America, a growing cadre of domestically trained intensive care physicians is now assuming leadership roles in ICU education and clinical care in the country, where only a few years ago no such opportunities existed. A similar project has been established successfully to train nurses in emergency and critical care medicine in Ethiopia [62].

Dedicated and sustainable partnerships at national and international levels incorporating both vertical and horizontal planning, such as the East Africa Training Initiative, require funding, enormous coordination, and sustained buy-in from numerous parties with diverse interests. Consequently, such partnerships are likely less feasible and more expensive to establish; however, they are more likely to have lasting success. Partnerships between individual institutions in resource-limited settings and professional societies in high-income countries are also possible but may lack sustainability. A serious risk to such partnerships is "brain drain," the emigration of well-trained and specialized healthcare workers from resource-limited to resource-rich settings or from low- and middle-income to high-income countries [40]. Solutions to the "brain drain" are complex and must involve systematic national programs to facilitate return of well-educated emigrated healthcare professionals to their home countries.

Small-scale initiatives, such as intermittent, institution-level ICU training courses like the "Fundamental Critical Care Support" course and others, are least likely to provide long-term benefit given their temporary nature. The teaching content may be difficult to implement in some resource-limited settings. Furthermore, start-up costs for formal courses, especially the ones developed in high-income countries, may exceed local budgets [52]. Focused critical care teaching courses, such as BASIC for Developing Health Systems, which is free and nonproprietary, have been developed and adjusted to resource-limited healthcare systems [63, 64]. Remote education via telemedicine may play a role in the future to reduce costs and improve availability of training options. We could not identify any published safety concerns to the implementation of educational interventions in ICUs in resource-limited settings.

We suggest that all healthcare professionals working in ICUs be specifically trained in the care of the critically ill patient (2C). Unless national or regional specialty training programs in intensive care medicine are available, we suggest that training of ICU physicians, nurses, and allied healthcare professionals occurs through longitudinal, multimodal programs coordinated by partnerships between Ministries of Health, national and international professional societies, nongovernmental organizations, as well as institutions with well-established programs in ICU training (2D). We recommend that such ICU training programs adhere to validated, international standards of intensive care medicine, but that they be adapted to local needs and resources (1C). 


\subsection{Electricity}

Modern ICUs provide around-the-clock, life-sustaining therapies often by the use of electricity-driven machines such as mechanical ventilators, syringe pumps, or extracorporeal therapies. Unexpected power cuts interrupt these therapies and may result in significant harm to or death of critically ill patients. Consistent and reliable electrical power supply is therefore a key logistical requirement of every ICU. However, electricity supply in resource-limited settings is often inconsistent. Major challenges include wide voltage fluctuations, which are deleterious to electricity-driven medical equipment. In many resource-limited settings, electrical power cuts occur on a regular basis and backup electrical sources are frequently absent. In a survey of 231 health centers in 12 African countries, only $35.1 \%$ of facilities were reported to have a reliable electricity supply and $56.7 \%$ had a backup power source such as a generator. The same survey showed that $16.5 \%$ of healthcare facilities did not have any electricity supply [65]. From personal experiences of one of the authors (AP) in 2011, the national public hospital in South Sudan sometimes had to function without electricity for days, limiting hospital services to dispensing medications and making already hot inpatient wards unbearable since fans were not working. Basic clinical services during these periods were performed by flashlight in the evening and not at all at night. Ensuring continuous electric supply is therefore imperative for ICUs to function effectively.

Voltage surges can be attenuated by installing voltage stabilizers into the main electrical supply line(s) of the ICU. Power cuts can be bridged by backup electrical sources, including batteries. Although multiple technical options exist (including solar power sources), fuel- or diesel-driven generators are the most commonly available technical solution in resource-limited settings. It is important to install an electrical backup source that provides adequate electrical power to supply essential medical apparatus in the ICU (e.g., mechanical ventilators, oxygen concentrators, syringe pumps delivering catecholamine agents) and other important machines (e.g., air compressor supporting the pressurized air system). Even when such backup power supplies are available, the time delay between mains power cut and startup of the backup supplies can be a limiting factor. Since even brief power cuts cause electrical equipment to shut down, backup sources that start automatically and immediately are crucial. Using battery-equipped equipment with short (30-60 min) automatic emergency electrical supply can help to mitigate patient harm. If backup sources must be started manually, protocols must be in place to guide ICU workers how to act in response to abrupt interruptions of life-sustaining therapies. Such protocols should ideally focus on three steps in a descending priority: (a) compensation of stopped mechanical ventilators (e.g., by manual bagging), (b) compensation of stopped catecholamine infusions (e.g., by injecting adrenaline into gravity infusions with titration of drops per minute), and (c) compensation of interrupted oxygen supply if oxygen concentrators are used for oxygen supply (e.g., by activating backup oxygen cylinders). It is important that these protocols can be implemented during daylight and nighttime (e.g., availability of functioning flashlights is essential) and that the ICU staff, particularly the nurses and nurse assistants, is adequately 
trained to implement them. Periodic mock "drills" may help to ensure smooth implementation in the event of an actual event.

Solar power has great potential for ICUs in resource-limited settings, especially given that many of these settings are located in tropical, sunny environments. Solar panel installation was associated with a significant reduction in mean inpatient pediatric mortality in a single-center, retrospective, before-and-after observational study in Sierra Leone [66]. An observational, proof-of-concept study in Uganda also demonstrated improvements in physiologic variables related to respiratory failure after solar panels were installed to power oxygen concentrators in a pediatric ICU [67]. These improvements were consistent even on cloudy days.

The greatest barrier to ensure adequate electrical supply to an ICU in a resourcelimited setting is financial. While voltage stabilizers are not costly and are readily available even in resource-limited settings, generators and other backup power sources are expensive, especially with automatic bridging functions. Diesel generators large enough to function through sustained power cuts require steady supply of fuel, which itself can be cost-prohibitive or in short supply. Another commonly faced challenge is maintenance of these systems, which requires technical expertise. Particularly during nighttime when technicians are not readily available, the ICU/ hospital staff needs to be familiar with activation of the available backup power source if activation does not occur automatically, a situation that poses logistical and safety challenges when the primary concern is stabilization of critically ill patients. When exposed to extreme weather conditions, generator malfunctions can occur and require skilled local technicians for repair.

A stable electricity supply is an essential infrastructural component of an ICU (ungraded). We recommend that ICUs use voltage stabilizers in case voltage fluctuations endanger the function of electrical medical equipment (1D). We recommend that adequate backup electrical sources be available to bridge power cuts (1C). We suggest that these backup electrical sources take over electricity supply automatically allowing for (near) continuous functioning of life-sustaining medical equipment (2D). We recommend that ICUs with no adequate backup electrical source have protocols in place guiding ICU staff how to bridge life-sustaining therapies during power cuts (1D).

\subsection{Oxygen}

The World Health Organization considers oxygen fundamentally important and lists it on page one of the Essential Medication List [67]. In 2015, the Lancet Commission on Global Surgery revealed that approximately one quarter of hospitals surveyed in resource-limited countries lack sufficient oxygen supply [68]. This analysis reinforced previous data reporting similar deficiencies in multiple resource-limited settings across the world $[65,69,70]$. Since severity of hypoxemia correlates with mortality [71] and often goes undiagnosed in resource-limited settings [72], ensuring adequate oxygen supply to ICUs in resource-limited settings is of critical importance. 
There are three commonly used methods to supply ICUs in resource-limited settings with oxygen: oxygen cylinders, oxygen concentrators, and centralized, piped oxygen systems [73]. Oxygen cylinders provide pressurized oxygen at variably high flow rates but—depending on their size —only do so for a limited period. They do not require electrical power supply but do require pressure regulators and flowmeters to deliver oxygen safely to the patient. Oxygen cylinders are purchased or rented from supply companies and refilled at central distribution points, often making long transportation times to (remote) healthcare facilities necessary. They are generally easy to use, but problems include oxygen leakage from the adaptors (varying from 10 to $70 \%$ of the entire cylinder oxygen content), difficulty moving due to size and weight, and sometimes confusion with the local color coding system [74]. Oxygen concentrators are devices which purify oxygen $(>90 \%)$ from ambient air by absorbing nitrogen onto zeolite membranes. Most concentrators deliver oxygen flow rates of up to $6 \mathrm{~L} / \mathrm{min}$. While this is typically enough to deliver oxygen noninvasively to (one to three) moderately unwell neonates or small children, it may not be enough in critically ill older children or adult patients. In contrast to oxygen cylinders, oxygen concentrators depend on a continuous electrical power supply. They also require technical maintenance including regular filter changes. Not all models of oxygen concentrators are technically suitable for sustained use in a tropical environment [75]. Centralized, piped oxygen systems typically deliver pressurized oxygen through wall outlets to bed spaces in the ICU. These systems are supplied by either a liquid oxygen tank, an oxygen concentrator, or several large oxygen cylinders. Proper functioning of centralized oxygen systems depends on adequate engineering expertise and technical maintenance. Specifically, pipeline conditions (presence and severity of gas leak) and diameter (to ensure adequate gas flow), compatible wall outlets, and the presence of shutoff valves must be considered. All three modes of oxygen supply to an ICU require the presence of a backup oxygen source in case of premature emptying (e.g., oxygen cylinders, centralized oxygen system supported by oxygen cylinders), electrical power cuts (e.g., oxygen concentrators), or technical defects (e.g., oxygen concentrators, centralized oxygen system). In many resource-limited settings, oxygen cylinders are used as backup oxygen systems.

Most modern mechanical ventilators depend on pressurized air and oxygen supply. Although oxygen cylinders may be used, doing so may require frequent exchange, particularly at high minute volumes or inspiratory oxygen concentrations. Therefore, centralized, pressurized oxygen and air systems appear most practical to run these types of ventilators. Selected types of mechanical ventilators and the majority of noninvasive (home) ventilators generate their driving pressure by internal air compressors and do not depend on a pressurized gas supply. When using these ventilators, oxygen can be delivered to the Y-piece or the inspiration tubing using either an oxygen cylinder or an oxygen concentrator. Oxygen concentrators are unable to serve as a pressurized oxygen source to run mechanical ventilators but can be used to enrich the oxygen concentration of inspiratory breaths delivered by compressor-driven ventilators. Although the latter practice results in unclear 
inspiratory oxygen concentrations, the oxygen flow of the oxygen concentrator can be titrated to achieve a desired blood oxygen saturation.

Taking the aforementioned conditions into account, the choice of the most appropriate method to supply an ICU with oxygen depends on site-specific requirements and conditions. A non-ICU study from The Gambia found that cylinders were better than concentrators due to local factors at 10 out of 12 hospitals studied. The authors suggested that concentrators are most advantageous when electrical power is reliable; cylinders may be preferable when power supply is erratic but only when weighed against substantial transportation and delivery costs [76]. Additionally, oxygen concentrators cannot be used to run mechanical ventilators that depend on a pressurized oxygen source as they generate insufficient oxygen flows and pressures.

Installation and maintenance of oxygen systems in an ICU in a resource-limited setting face multiple challenges. While oxygen cylinders are commonly available, also in remote areas, oxygen concentrators are often not locally available and can only be purchased in metropolitan areas or from overseas. Although some materials to set up centralized oxygen systems are ubiquitously available (e.g., copper pipes), key parts, such as wall outlets or liquid oxygen tanks, are not. Copper pipes are also prone to theft [77]. Maintenance of all oxygen supply systems is frequently impeded by financial constraints and a shortage of workers with sufficient training, equipment, and technical experience [76].

A before-after study evaluated the feasibility and outcome effects of improved oxygen delivery on case fatality rates of children with pneumonia admitted to five hospitals in Papua New Guinea. After introduction of pulse oximeters to detect hypoxemia and installation of oxygen concentrators, the risk of death for a child with pneumonia was reduced by $35 \%$ [risk ratio 0.65 (CI 95\%, 0.52-0.78) compared to the time period before oximeters and oxygen concentrators were made available]. The implementation costs were estimated to be USD \$51 per patient treated, USD \$1673 per life saved, and USD \$50 per disability-adjusted life year averted [78]. Multiple studies from resource-limited settings demonstrated greater cost reductions with oxygen concentrator systems compared to cylinders and generators. In Papua New Guinea, the overall 2-year cost estimate for cylinders, capable of producing 35,000 L/day, was approximately USD \$205,000 when compared to three oxygen concentrators (USD $\$ 82,400$ ) and an oxygen generator system (USD \$390,000), both capable of producing 60,000 L/day, [73]. In The Gambia, annual costs for cylinders at one hospital were USD \$152,747 vs. USD \$18,742 for concentrators with $24 \mathrm{~h}$ availability of grid power [76]. A different 8-year, singlecenter analysis from The Gambia estimated that installation of oxygen concentrators with a reliable backup power supply saved $51 \%$ on oxygen supply costs compared to cylinders (assuming $2 \mathrm{~L} / \mathrm{min}$ flow rate). When accounting for air leaks and the estimated costs of backup power supply maintenance, the authors estimated total savings of USD $\$ 45,000$ over 8 years [74]. Given regional variations in supply chains, local engineering and maintenance capabilities, electrical power supply, and other factors, these cost analyses cannot be applied uniformly to other resourcelimited settings. A decision support algorithm to determine the best mode of oxygen 
supply to an individual ICU in a resource-limited setting has been suggested by some authors [76].

Oxygen is an essential medication for critically ill patients, and an adequate oxygen supply is a crucial infrastructural component of an ICU (ungraded). We recommend that ICUs in resource-limited settings choose the type of oxygen supply (concentrators, cylinders, centralized system) based on site-specific conditions and requirements (1B). We suggest that, when feasible, oxygen be supplied by centralized, piped systems to ICUs when mechanical ventilators are used (2D).

\subsection{Hygiene}

While healthcare-acquired infections are prevalent throughout the world, the burden is highest in resource-limited settings. The World Health Organization estimates that healthcare-associated infection rates are roughly 20 times higher in low- and middle-income countries compared to high-income countries [79]. In ICUs specifically, a meta-analysis reported an overall incidence of ICU-associated infections of 47.9 per 1000 patient days in developing countries. This was three times greater than the prevalence reported from the United States. Surgical site infections were most common, but device-associated infections were highly prevalent as well [80]. Healthcare-associated infections can be transmitted via myriad mechanisms. Many, if not most, can be prevented easily with simple measures. However, lack of hygienic facilities, insufficient training of staff, and lack of administrative oversight (e.g., by hospital-level and national-level infection control measures) are likely to contribute to the deleteriously high rates of nosocomial infection rates in ICUs in resourcelimited settings [81].

In line with findings from resource-rich settings, several studies originating in resource-limited settings suggest that hand hygiene is the most effective method of reducing healthcare-acquired infections. Healthcare workers can contaminate hands and medical devices with even a single contact with the patient or his/her immediate surroundings. Contaminant transfer to other patients and healthcare workers is common if hand hygiene is inadequate or not performed [82]. Innumerable challenges to improving hand hygiene in resource-limited settings have been identified, but reasons vary from location to location [83]. Convincing evidence indicates that implementation of multimodal hand hygiene programs can not only improve hand hygiene compliance but also reduce ICU-acquired infection rates. A prospective observational study involving 99 ICUs in 19 resource-limited countries demonstrated a significant $23.1 \%$ overall increase in hand hygiene compliance after implementation of a multidimensional hand hygiene program involving administrative support, supply availability, education and training, workplace reminders, process surveillance, and performance feedback [84]. These findings have been replicated in geographically diverse locations including India [85], China [86], and Mexico [87]. A prospective study in six Colombian ICUs demonstrated a significant reduction (12.7\% annually during the 4-year study period) in central line-associated bloodstream infections after introduction of a targeted hand hygiene program that included 
installation of alcohol-based hand rub dispensers adjacent to each ICU bed and regular feedback to healthcare workers [88]. In a Vietnamese tertiary ICU, the combination of hand hygiene and antimicrobial mixing reduced MRSA infections significantly, but not the incidence of the four hospital-acquired gram-negative infections studied.

Several large studies from resource-limited and resource-rich countries reported superior efficacy of hand rubbing with alcohol-based solutions over handwashing with antiseptic soap to reduce hand contamination. A study including three Egyptian ICUs and a renal dialysis unit found that hand rubbing with alcohol-based liquids or gels resulted in a higher reduction of bacterial counts on the hands of ICU staff compared to handwashing with soap and water $(77-99 \%$ vs. $30 \%, p<0.001)$ [89]. These results are in line with the findings of a randomized controlled trial conducted in French ICUs that observed a $26 \%$ reduction in bacterial hand contamination when using alcohol-based hand rub compared to soap and water [90].

During the West African Ebola virus disease outbreak, chlorine-based hand hygiene was commonly used following patient encounters in Ebola treatment centers and in affected communities. This practice is supported by an observational study conducted in Ebola treatment centers in Sierra Leone demonstrating elimination of Ebola virus RNA from contaminated personal protective equipment following treatment with locally produced chlorine solutions [91]. Although this study did not determine whether detection of Ebola RNA on personal protective equipment translated to an increased risk of infection, it can be inferred that reducing contamination is likely to decrease the risk of iatrogenic infection. Although frequent hand hygiene with chlorine-based solution may increase skin irritation, the severity of irritation is little different than with use of soap and water and alcohol-based solutions based on a randomized trial comparing different handwash regimens [92].

Non-sterile, clean examination gloves function as a protective barrier for medical staff who potentially encounter blood, body fluids, or other possibly infectious material. The bacterial bioburden of non-sterile examination gloves is very low [93] and does not differ between newly opened and nearly empty boxes [94]. A randomized controlled trial performed in US ICUs reported that the total bacterial colony counts of gloved hands were not different if hand hygiene was performed before non-sterile examination gloves were donned or not, suggesting that hand hygiene before donning non-sterile gloves is unnecessary [95]. Several studies, however, indicate that contaminated examination gloves can spread bacterial pathogens from healthcare workers to patients [96]. Furthermore, examination gloves do not avoid bacterial contamination of healthcare workers' hands due to microlesions [97]. Based on these results, the WHO emphasizes that wearing gloves does not replace the need for subsequent hand hygiene [83]. Reuse of medical examination or surgical gloves is commonplace in many resource-limited settings [ref], but the limited studies available suggest that reprocessing and reuse of disposable gloves may be harmful to patients and healthcare professionals. A laboratory-based study from Kenya comparing sterility and physical integrity of reprocessed plastic surgical gloves compared to new, sterilized surgical gloves demonstrated alarmingly reduced physical integrity and sterility of the reprocessed gloves [98]. 
A before-after study from Pakistan found that the use of (plastic) shoe covers by medical staff and visitors was not helpful in preventing infections with common ICU pathogens or improving the outcome of critically ill patients [99]. Further infection control measures such as fogging and spraying of disinfectants, the use of disinfection or sticky mats, and routine use of face masks or caps by ICU staff or visitors have not been shown to influence infection rates in ICUs [100]. No trials from resource-limited settings on the routine use of gloves, gowns, and aprons to prevent nosocomial or cross infection in critically ill patients were identified. Three large randomized trials from the United States concluded that the universal use of gloves and gowns for all patient contact compared with usual care (adequate hand hygiene and use of gloves in case of contact with blood, body fluids, or other contaminants) did not reduce adverse events or the transmission rate of multiresistant bacteria [101-103]. Similarly, a Cochrane meta-analysis primarily consisting of studies from resource-rich settings could not identify evidence that overgowns used by staff or visitors are effective in limiting death, infection, or bacterial colonization in infants admitted to neonatal wards or intensive care units [104].

Critically ill patients with known or suspected airborne, droplet, or contact infections require specific hygienic precautions. Although no randomized controlled trials were identified by our literature search, (cohort) isolation of patients with airborne (e.g., Mycobacterium tuberculosis) or droplet infections (e.g., influenza virus, measles, varicella zoster virus, Neisseria meningitidis, coronavirus) in separate rooms is recommended by international and national guidelines both in resource-rich and resource-limited settings $[105,106]$. In addition to standard hygienic measures, adequate hand hygiene in particular, the use of masks has been recommended to protect healthcare workers caring for (critically ill) patients with acute respiratory infections. Despite surrogate exposure studies indicating that N95 respirators are associated with less filter penetration and inward leakage than surgical masks, large clinical trials and meta-analyses failed to show that N95 respirators are superior to surgical masks in protecting healthcare workers against influenza during routine care [107-109]. The Centers for Disease Control and Prevention recommends use of N95 disposable, powered air-purifying, or self-contained breathing apparatus respirators for healthcare workers caring for patients with tuberculosis [110]. In addition to isolation, patients with highly contagious infectious diseases, such as viral hemorrhagic fever or smallpox infection, require specific hygienic precautions. In its latest guidelines on personal protective equipment for use in a filovirus disease outbreak, the World Health Organization recommends the use of face shields or goggles, a fluid-resistant head cover and surgical mask, double gloves, and protective body wear, as well as waterproof aprons and boots, in addition to regular on-duty clothing [111].

A large before-after study in North America showed that the use of full-barrier precautions during insertion of central venous catheters, in addition to adequate hand hygiene when handling catheters, significantly reduced the risk of central venous catheter-related bloodstream infections by up to $66 \%$ over the 18 -month study period [112]. Full sterile barrier precautions include the use of a cap, mask, 
sterile drapes, a sterile gown, and sterile gloves following adequate skin preparation and hand hygiene; these components have not been studied separately. Other observational studies confirmed these findings and suggest that the rate of central venous catheter-related bloodstream or other device-related infections can be minimized with the use of appropriate hygienic precautions [113-117].

No randomized controlled trials from resource-limited or resource-rich settings on the architectural design of ICUs to prevent transmission of microbial pathogens were identified by our search and a previous review of the literature [118]. A prospective study from the United Kingdom reported that isolation of patients colonized or infected with methicillin-resistant Staphylococcus aureus in single rooms or cohorted bays did not reduce cross infection as long as adequate hand hygiene measures were maintained [119]. In contrast, studies suggest that isolation of critically ill patients in rooms that are poorly visualized by staff is likely related to a higher risk of death [120].

National and international guidelines recommend isolation of patients with highly contagious infectious diseases (e.g., tuberculosis, influenza, measles, rubeola infection, varicella zoster infection, hemorrhagic virus disease) or severe immune suppression (e.g., neutropenia, burns, transplant) [106, 110]. Atmospheric pressure in isolation rooms should be controllable to target negative pressure when isolating patients with airborne infections and positive pressure when caring for patients who require protective isolation [106, 110]. A survey-based study of 83 ICUs in resourcelimited Asian countries (Bangladesh, India, Nepal, Pakistan, and the Philippines) found that 34 did not have single rooms and 64 did not have negative pressure rooms [121]. A study from Peru reported that upper-room ultraviolet lights and negative air ionization prevented most airborne tuberculosis transmission detectable by guinea pig air sampling [122]. These observations have recently been confirmed by a study from South Africa suggesting that upper-room ultraviolet light is an effective, lowcost intervention for use in tuberculosis infection control in high-risk clinical settings [123]. Regarding the architectural design of new or newly renovated ICUs, consensus-based guidelines published by the Indian Society of Critical Care Medicine recommend the installation of filter-containing central air-conditioning systems with a minimum of six total air changes per room per hour (filter efficiency $99 \%$ down to $5 \mu \mathrm{m}$ ); clearly demarcated routes of traffic flow through the ICU; adequate space around and between beds; an adequate number of washbasins; a separate medication preparation area; separate areas for clean, soiled, and waste storage/disposal; and adequate toilet facilities [124]. Alcohol hand rub dispensers are recommended to be placed at the ICU entry and exits and at every bed space and workstation [124].

Despite the clear evidence that the use of alcohol-based hand rub solutions reduces the risk of infection transmission [83], commercial alcohol-based hand rubs are often unavailable in resource-limited settings [82]. A study from Egypt suggests that locally prepared alcohol-based hand rubs are similarly effective to commercial products [89], so local preparation of these products may be feasible and potentially more affordable than purchase of foreign-made products, with recipes readily available [125]. Locally produced chlorine-based handwashing solutions are also 
effective for decontamination in Ebola virus disease [92], but careful attention must be paid to varying shelf lives among solutions of differing chemical composition, especially in hot environments [126]. Hand hygiene dispensers are commonly used to supply ICU workers in resource-rich countries with alcohol-based hand rub solutions. These dispensers are, however, often unavailable or restricted to the operating theaters in hospitals in resource-limited settings. In addition, they depend on regular refilling by dedicated staff, which may be problematic in understaffed ICUs. In the absence of adequate hand hygiene dispensers, small pocket bottles containing alcohol-based hand rub solutions can be carried, used, and refilled by each ICU worker (Fig. 3.1). A multifaceted hand hygiene program (including upgrading hand hygiene facilities, provision of alcohol-based hand rub at point of care, hand hygiene campaigns, continuous hand hygiene education) not only reduced the incidence of hospital-acquired infections in 17 Vietnamese ICUs but also proved to be costeffective [127]. Although a cluster-randomized, crossover trial in rural Kenya failed to show differences in surgical site infections between handwashing with alcohol or soap and water $(8.3$ vs. $8 \%)$ in 3133 patients undergoing clean or clean-contaminated surgery, the use of alcohol-based hand rubbing solutions was as feasible and affordable (€4.6 vs. €3.3 per week) as handwashing with soap and water [128]. Religious beliefs do not influence the use of alcohol-based hand rub solutions for hand hygiene but may impact implementation effectiveness [129].

Respirator masks are often unavailable and underused in resource-limited settings where acute respiratory infections are highly prevalent. Given cost concerns and the unclear scientific benefit of using N95 respirators compared with surgical masks [107], it appears advisable that if N95 respirators are in short supply they should be reserved to protect healthcare workers caring for patients with tuberculosis or other airborne infectious diseases or when caring for patients with dropletspread infections during aerosol-generating procedures or when caring for patients in very hot and humid environments for long periods when surgical masks may become wet and ineffective (e.g., during the Ebola epidemic). Importantly, cloth
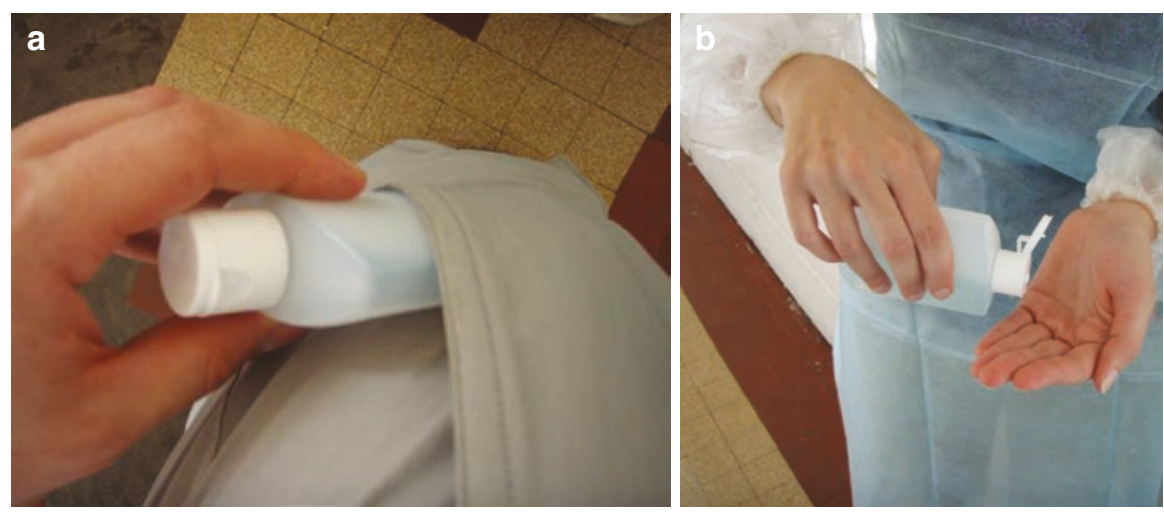

Fig. 3.1 Pocket bottles filled with alcohol-based hand rub for hand hygiene in ICUs in resourcelimited settings (Courtesy of Martin W. Dünser, MD) 
masks are prone to moisture retention and poor filtration when reused [130]. As suggested by a randomized controlled trial, they should not replace surgical masks in high-risk situations [131]. One striking challenge during the most recent Ebola virus disease epidemic was the shortage of personal protective equipment faced by healthcare workers caring for diseased patients in West Africa, as global fears of a disease spread rose and resource-rich countries filled their stocks with protective body suits. Since single-use, disposable sterile gowns and drapes, commonly used for invasive procedures in ICUs in resource-rich settings, are expensive and mostly unavailable in resource-limited countries, autoclavable gowns and cloths may be used instead for the majority of common ICU illnesses. For Ebola virus disease, the WHO emphasizes use of disposable personal protective equipment [132].

We recommend that ICUs have available an adequate number of and easily accessible facilities for handwashing/hand hygiene (1A). We recommend hand hygiene after each patient contact with an alcohol-based solution (1A) or, for Ebola virus disease specifically, with chlorine-based solution (1C). In case alcohol-based solutions are unavailable, we recommend using soap and water for handwashing (1A). Alcohol hand rub solutions may be produced locally and carried in small bottles by each healthcare worker (ungraded). We recommend that non-sterile, clean examination gloves for self-protection of medical staff be available (1C). Importantly, gloved hands can equally transmit infectious pathogens and that the use of gloves does not replace the need for subsequent hand hygiene (ungraded). We recommend the availability of masks, caps, sterile gowns, sterile drapes, and sterile gloves for invasive procedures such as insertion of central venous catheters (1A). We recommend that ICUs and hospitals in areas where highly contagious infectious diseases (e.g., tuberculosis, Ebola virus disease) are endemic have rapid access to adequate quantities of personal protective equipment as recommended by the World Health Organization and the Centers for Disease Control and Prevention (1C). We suggest that hospitals develop individual policies and procedures for reuse of disposable personal protective and other medical equipment (2C). When ICUs are renovated or newly built, we suggest compliance with national and international best-practice recommendations on ICU architectural design (2D).

\subsection{Equipment}

The very nature of an ICU warrants a higher reliance on technical equipment, devices, and other technologies compared to the general medical ward. Irrespective of the geographic location or level of resource limitation, technical equipment constitutes an essential component of ICU-level patient care. What specific types of technical equipment are essential, however, remains undetermined. In resourcelimited settings, multiple challenges in terms of equipment procurement and maintenance exist [133]. For example, can the technical equipment run with frequent electric current interruptions? How reliable are the supply chains to obtain or replace the equipment and are local technicians available for repairs? Is donated equipment relevant in the local context and are clinicians educated on how to use it [134]? 
Given these considerations, resource-limited hospitals and health systems must find and fund equipment purchase or donation sustainably and in the most targeted manner possible.

No large clinical trial has so far shown a reproducible survival benefit related to the use of a single monitoring device in critically ill patients. Monitors improve the care of the critically ill only if healthcare staff make timely and appropriate changes in the therapeutic management based on data from monitors. In view of the fact that pathologic deviations of vital signs such as heart rate, respiratory rate, arterial blood pressure, and arterial oxygen saturation are associated with an increased risk of organ dysfunction and death [135-138], especially in settings where artificial life support is inconsistently available [139-145], it appears sensible to measure these parameters continuously or at regular intervals. A prospective, before-and-after interventional study including 447 ICU patients in a Tanzanian university hospital reported that a vital signs-directed therapy improved the acute management of patients with abnormal vital signs. While overall in-hospital mortality was unchanged before and after the intervention, critically ill patients with arterial hypotension experienced a lower post-implementation mortality (69.2 vs. 92.3\%, $p=0.02$; number needed to treat 4.3) [146].

No conclusive evidence-either from resource-limited or resource-rich settings - was identified to answer the question whether noninvasive or invasive blood pressure measurement is superior in critically ill patients. While a study performed in critically ill patients in an emergency department in a resource-rich country reported inaccuracy of oscillometric blood pressure measurements at hypotensive blood pressure ranges [147], a prospective multicenter study from France found a good discriminative power of noninvasive blood pressure measurements to identify arterial hypotension (mean arterial blood pressure $<65 \mathrm{mmHg}$ ) and track arterial blood pressure in 111 patients with shock [148]. A survey among US intensivists observed that $73 \%$ and $47 \%$ of respondents reported using noninvasive blood pressure measurements in hypotensive patients and patients on vasopressor support, respectively [149].

A recent Cochrane meta-analysis could not identify convincing evidence that the use of pulse oximetry conveys a significant survival benefit in perioperative patients [150]. However, a large, multicenter, before-and-after intervention study from Papua New Guinea observed a survival benefit associated with the systematic use of pulse oximetry to monitor and treat children with pneumonia, when coupled with a reliable oxygen supply [78]. In settings where blood gas analyzers are unavailable, the plethysmographic oxygen saturation relative to the inspiratory oxygen concentration $\left(\mathrm{SpO}_{2} /\right.$ $\mathrm{FiO}_{2}$ ratio) can be used for decision-making and continuous monitoring [151, 152].

A systematic review of the literature evaluated the benefit associated with the use of portable ultrasound devices in low- and middle-income countries [153]. Although several reports were identified describing the successful diagnosis, triage, and management of patients with complex, life-threatening conditions with the use of pointof-care ultrasound, no randomized controlled trial has so far evaluated the impact of ultrasound-guided diagnosis and treatment in resource-limited settings. A HaitianUS study demonstrated that tele-mentoring of non-physicians performing 
ultrasound in a resource-limited setting was feasible and adequate to make clinical decisions in the majority (89\%) of cases [58].

Our literature search did not identify any randomized controlled trials evaluating the effects of mechanical ventilators on mortality in critically ill patients both in resourcelimited and resource-rich settings. However, mortality of patients with hypoxemia who do not receive mechanical ventilatory support is extremely high, suggesting that mechanical ventilation associates with a survival benefit [152]. Observational evidence from ICUs in Vietnam suggest that general intensive care measures, including mechanical ventilation, can improve clinical outcomes $[154,155]$. A structured ICU training program that included modules on mechanical ventilation improved overall ICU mortality in two of three ICUs in India, Nepal, and Bangladesh [156].

Reports from India and Africa confirm the feasibility of noninvasive ventilation in resource-limited settings [157, 158]. A randomized controlled trial including four rural hospitals in Ghana found that continuous positive airway pressure application by local nurses significantly reduced respiratory rate and was not associated with complications in 70 children with respiratory distress [159]. A randomized controlled trial that was stopped early including 225 Bangladeshi children with severe pneumonia and hypoxemia found that the use of bubble continuous positive airway pressure reduced the risk of treatment failure and death compared with standard lowflow oxygen therapy [160]. These results were confirmed by studies from India and Malawi $[161,162]$. No randomized controlled trials on the use of end-tidal carbon dioxide monitoring in resource-limited settings were identified. Studies from both resource-limited and resource-rich settings prove that end-tidal carbon dioxide measurement is a reliable technique to verify endotracheal tube placement and an adequate tool to monitor mechanical ventilation [163-165]. Although differences between arterial and end-tidal carbon dioxide values are common and vary individually $[166,167]$, the trends over time appear helpful to guide mechanical ventilation, particularly when arterial blood gas analyzers are unavailable [168-170].

Renal replacement therapy improves short- and long-term survival of patients with severe acute renal injury [171, 172]. Recommendations regarding renal replacement therapy for critically ill patients in resource-limited settings are discussed in another chapter in this book [173].

Abnormal blood glucose levels and increased blood lactate levels have both been associated with increased mortality in the critically ill in resource-limited and resource-rich settings [174-184]. A Ugandan multicenter study recorded an incidence of hypoglycemia of $16.3 \%$ among 532 sepsis patients. In this study, hypoglycemia was an independent risk factor for in-hospital mortality and could not be adequately predicted by clinical examination [185]. Hypoglycemia is a well-known complication of malaria, particularly in children [186] and those treated with quinine [187]. Although our literature search did not reveal a randomized controlled trial showing that measurement of blood glucose is associated with improved outcome, it is sensible to assume that detection of dysglycemic episodes is associated with improved care. While studies from resource-limited settings suggest that results of point-of-care methods to measure blood glucose levels are closely correlated with those of laboratory measurements [188, 189], some studies from 
resource-rich settings have highlighted inaccuracies of point-of-care devices in lower blood glucose ranges [190]. A recent international multicenter study, however, demonstrated that bedside blood glucose monitoring systems were acceptable for use in critically ill patient settings when compared to a central laboratory reference method [191]. Similarly, lactate levels as measured by a point-of-care blood lactate analyzer reliably predicted mortality in Ugandan sepsis patients [179], as well as febrile children in Tanzania [180]. No randomized controlled trials from resource-limited settings were identified evaluating the outcome effects of lactate measurements or lactate-guided interventions in critically ill patients. Although limited by insufficient information size, a meta-analysis with sequential analysis of randomized controlled trials originating in resource-rich countries suggested that the use of lactate clearance as a goal to guide resuscitation was associated with a reduction in the risk of death in adult patients with sepsis [192].

Similar to glucose and lactate measurement, our literature search failed to find studies demonstrating improved outcomes for arterial or venous blood gas measurement. A Swiss prospective observational study demonstrated that lower $\mathrm{pH}$ was an independent predictor of 12-month mortality in emergency department patients presenting with dyspnea, but arterial blood gas analysis itself had very limited diagnostic value [193]. According to international consensus definitions developed in high-income countries, measurement of the partial pressure of oxygen is required to diagnose the acute respiratory distress syndrome (ARDS) [194]. Similar recommendations have been made for sepsis-induced ARDS diagnosis in resource-limited settings [152], supported by observational evidence to show that patients with increasing severity of ARDS as determined by the arterial partial pressure of oxygen to fraction of inspired oxygen ratio have higher mortality and higher noninvasive ventilation failure rates [195].

The availability of vital signs monitors, mechanical ventilators, renal replacement devices, and point-of-care tools in ICUs varies substantially between resourcelimited regions [196-204]. Several studies suggest that hospitals in middle-income countries and metropolitan areas of low-income countries have more technical equipment available than healthcare facilities in low-income countries and rural areas [200-204]. Except for remote areas [202, 205], the availability of vital signs monitors and glucometers appears consistently high; point-of-care laboratory facilities and renal replacement equipment are strikingly unavailable in certain areas [202-204]. Common challenges of installing and maintaining technical equipment in ICUs in resource-limited settings are high investment costs depending on the regional availability of medical retailers, the need for reliable electrical power supply, disposable materials (e.g., ECG electrodes, printer paper), as well as technical maintenance and repair in case of device malfunction or breakdown [206]. A mathematical model based on cost-effectiveness threshold and the results of previous studies concluded that the perioperative use of pulse oximeters is cost-effective in resource-limited settings [207].

In addition to challenges faced with installation and maintenance of vital signs monitors and as previously described, mechanical ventilators additionally require a reliable oxygen and/or (pressurized) gas supply as well as structured training of 
healthcare staff. In contrast to invasive mechanical ventilation, noninvasive mechanical ventilation appears to be feasible and safe in resource-limited settings after short, structured education of ICU staff [159, 208]. A study from India even reported that the use of noninvasive mechanical ventilation to treat patients with acute exacerbations of chronic obstructive pulmonary disease in non-ICU wards was both feasible and cost-effective [209]. Although continuous positive airway pressure and/or high-flow oxygen devices may be implemented in clinical practice with relatively low implementation costs and a concise staff training, its maintenance may consume high amounts of oxygen, particularly when used at high inspiratory oxygen concentrations in adults. Oxygen requirements in children are substantially lower due to lower minute ventilation.

Whereas both the implementation and maintenance costs to run point-of-care glucometers in the ICU are low, other point-of-care laboratory facilities (e.g., blood gas analyzers, including lactate measurements) critically depend on the local availability of (costly) supply materials (e.g., reactive agents), reliable electrical supply, as well as regular maintenance by skilled laboratory or medical technicians. Although cassette-based blood gas analyzers show a comparable accuracy to traditional blood gas analyzers [210] and require less technical maintenance, they are associated with much higher costs, particularly when large amounts of blood samples are analyzed. Separate point-of-care devices measuring blood lactate levels have been suggested as cheaper alternatives to blood gas analyzers in resourcelimited settings [189, 211]. Moreover, availability of blood gas analyzers is severely limited [212], and contemporary evidence from resource-rich and resource-limited settings suggest that arterial blood gas measurement may not be necessary to diagnose and to improve outcomes for ARDS [137, 213].

Acquisition of technical equipment should be guided by local availability and feasibility of routine maintenance (ungraded). We recommend that ICUs have basic vital signs monitors (including electrocardiogram, respiratory rate, oscillometric blood pressure, and pulse oximetry) available for each ICU bed (1C). We recommend that ICUs have one or more mechanical ventilators available (1C). These mechanical ventilators should also deliver noninvasive ventilatory modes, measure tidal volume and airway pressures, and support oxygen delivery (1B). We suggest that ICUs that provide invasive ventilatory support have facilities available to measure end-tidal carbon dioxide (2C) and to perform blood gas analysis (2C). We recommend that ICUs have point-of-care capabilities for measuring blood glucose (e.g., glucometers) (1B). We recommend that ICUs have capabilities for measuring blood lactate levels (1B). We suggest that ICUs have available point-of-care ultrasound devices (2C) and that key clinical staff undergo formal ultrasound training (2C).

\subsection{Quality}

The sepsis and intensive care literature is replete with examples of poor quality care [51]. The great challenge is how best to improve quality of care for critically ill patients in resource-limited settings when faced with countless financial, resource, 
and administrative constraints. A significant limitation is that sparse epidemiologic data detailing sepsis presentation and management in resource-limited settings have been published [214]. Without these data, it is difficult, if not impossible, to identify effective interventions that work at the population level. Various authors have developed general roadmaps for the future [215], but specific interventions demonstrating convincing improvements in intensive care in resource-limited settings are still lacking.

Regular documentation of the patient's history of care is a medicolegal requirement in almost all healthcare systems. Medical records are the integral repository of the patient's disease course, healthcare planning, and documentation of communications with other healthcare providers, the patient, and his/her family. Furthermore, medical records are used to assess compliance of care with institutional, national, or international guidelines and regulations. Although electronic data documentation has become commonplace in many ICUs in resource-rich settings and resulted in improved accuracy and legibility of documents, a meta-analysis failed to show that implementation of electronic medical records has a substantial effect on relevant ICU outcomes such as mortality, length of stay, or costs of care [216]. Although introduction of a daily goal form can improve communication between ICU healthcare professionals and possibly reduce ICU length of stay [217-221], a large, randomized, controlled, multicenter trial from a resource-limited setting failed to reproduce beneficial effects of a multifaceted quality improvement intervention with daily checklists, goal setting, and clinician prompting on in-hospital mortality of critically ill patients [222].

A multitude of quality improvement methods to implement and translate scientific evidence into clinical care have been published. Education, audit and feedback, protocols, bundles of care, and checklists are common tools studied to improve the quality of ICU and sepsis care. Most reports originate in resource-rich settings. A large nationwide educational effort to implement international sepsis guidelines using two care bundles was associated with improved guideline compliance and lower hospital mortality in Spain [223]. These results were confirmed by several other reports [224, 225], indicating that a higher compliance with international sepsis guidelines was directly and significantly associated with improved survival [226-228]. A large prospective interventional study in Uganda found that a bundled protocol to implement early monitored sepsis management improved survival of patients with severe sepsis in two hospitals [229]. A small observational cohort study in Haiti demonstrated improved process measures in septic care after implementation of a simplified sepsis protocol developed by the World Health Organization, although there was no mortality effect [230]. Similarly, two hospitalwide, protocol-based quality improvement programs significantly reduced the rate of catheter-associated urinary tract and catheter-associated bloodstream infections in Thailand [231, 232]. Checklists have been implemented successfully to optimize sepsis care [233] and high-risk procedures [234] in critically ill patients in resourcerich settings. A large international quality improvement project based on checklists to minimize preventable deaths, disability, and complications in critically ill patients is underway and includes several ICUs based in resource-limited settings [235]. 
Benchmarking is another accepted quality improvement concept in healthcare to identify performance gaps and to improve the quality of care based on anonymous comparison of quality indicators with other institutions and services. Although multiple benchmarking projects and ICU registries exist in resource-rich countries, no evidence currently supports that they translate into improved patient outcomes. A reduction in the standardized mortality ratio in Dutch ICUs occurring concurrently with the Dutch national benchmarking activities suggests that benchmarking of ICU performance indicators is a promising tool to improve quality of ICU care [236]. Quality and performance indicators of ICUs have been published by national and international societies in both resource-rich and resource-limited settings [237239]. While several national and international ICU registries and benchmarking projects exist in resource-rich countries [240], only a few national ICU registries exist in resource-limited settings, such as Sri Lanka [241] and Malaysia [242]. Similarly, internal and external clinical audits have been suggested as promising methods to improve quality of ICU care in resource-rich countries [243, 244], but consistent data from resource-limited settings are lacking.

Although implementation of protocols, bundles, and checklists into clinical practice requires a variable amount of funding, preliminary results of studies from resource-limited settings suggest that these interventions may prevent adverse events and complications [231, 232]. A delicate and important challenge of implementing protocols, care bundles, and checklists into clinical practice in ICUs in resourcelimited settings is the lack of safety data. Different disease pathologies, as well as absent treatment options (e.g., airway protection and mechanical ventilation), could well explain why certain interventions that were shown to improve patient outcome in resource-rich settings increased morbidity and mortality in resource-limited settings [215, 245-247]. This underlines the urgent need to test the efficacy and safety of adjusted care bundles and protocols to improve care of critically ill and sepsis patients in settings where resources are constrained [215, 248]. Another consideration is that quality control measure implementation may divert financial resources from clinical care. Although long-term reduction savings may occur due to avoidance of adverse events, the up-front expenditure may prove burdensome.

We recommend maintaining patient records and ICU documentation in accordance with national regulations and requirements (1D). We suggest that ICUs develop locally applicable bundles, protocols, and checklists to improve quality of care (2C). We suggest that ICUs systematically collect quality and performance indicators and participate in national/international benchmarking projects $(2 \mathrm{C})$.

\subsection{Conclusions}

We provide a series of simple, pragmatic recommendations for optimizing ICU infrastructure and organization in resource-limited settings. Understanding the great variability of technical, material, and human resources within and between these environments, each institution must determine the utility of implementing these recommendations based on local capabilities. Given the paucity of evidence, there remains a clear need for additional studies from resource-limited settings. 


\section{References}

1. Marshall JC, Bosco L, Adhikari NK, Connolly B, Diaz JV, Dorman T, et al. What is an intensive care unit? A report of the task force of the World Federation of Societies of Intensive and Critical Care Medicine. J Crit Care. 2017;37:270-6. https://doi.org/10.1016/j. jcrc.2016.07.015.

2. Schultz MJ, Dunser MW, Dondorp AM, Adhikari NK, Iyer S, Kwizera A, et al. Global Intensive Care Working Group of the European Society of Intensive Care Medicine. Current challenges in the management of sepsis in ICUs in resource-poor settings and suggestions for the future. Intensive Care Med. 2017;43:612-624. https://doi.org/10.1007/s00134-017-4750-z.

3. Yoo EJ, Edwards JD, Dean ML, Dudley RA. Multidisciplinary critical care and intensivist staffing: results of a statewide survey and association with mortality. J Intensive Care Med. 2016;31:325-32. https://doi.org/10.1177/0885066614534605.

4. Wilcox ME, Chong CA, Niven DJ, Rubenfeld GD, Rowan KM, Wunsch H, et al. Do intensivist staffing patterns influence hospital mortality following ICU admission? A systematic review and meta-analyses. Crit Care Med. 2013;41(10):2253-74. https://doi.org/10.1097/ CCM.0b013e318292313a.

5. Barrett H, Bion JF. An international survey of training in adult intensive care medicine. Intensive Care Med. 2005;31(4):553-61. https://doi.org/10.1007/s00134-005-2583-7.

6. CoBaTrICE Collaboration. The educational environment for training in intensive care medicine: structures, processes, outcomes and challenges in the European region. Intensive Care Med. 2009;35(9):1575-83.

7. van der Sluis FJ, Slagt C, Liebman B, Beute J, Mulder JW, Engel AF. The impact of open versus closed format ICU admission practices on the outcome of high risk surgical patients: a cohort analysis. BMC Surg. 2011;11:18.

8. Kerlin MP, Adhikari NK, Rose L, Wilcox ME, Bellamy CJ, Costa DK, et al. ATS Ad Hoc Committee on ICU Organization. An official American Thoracic Society Systematic review: the effect of nighttime intensivist staffing on mortality and length of stay among intensive care unit patients. Am J Respir Crit Care Med. 2017;195(3):383-93.

9. Banerjee R, Naessens JM, Seferian EG, Gajic O, Moriarty JP, Johnson MG, et al. Economic implications of nighttime attending intensivist coverage in a medical intensive care unit. Crit Care Med. 2011;39(6):1257-62.

10. Bray K, Wren I, Baldwin A, St Ledger U, Gibson V, Goodman S, et al. Standards for nurse staffing in critical care units determined by: The British Association of Critical Care Nurses, The Critical Care Networks National Nurse Leads, Royal College of Nursing Critical Care and In-flight Forum. Nurs Crit Care. 2010;15(3):109-11.

11. West E, Barron DN, Harrison D, Rafferty AM, Rowan K, Sanderson C. Nurse staffing, medical staffing and mortality in intensive care: an observational study. Int J Nurs Stud. 2014;51(5):781-94.

12. Dang D, Johantgen ME, Pronovost PJ, Jenckes MW, Bass EB. Postoperative complications: does intensive care unit staff nursing make a difference? Heart Lung. 2002;31(3):219-28.

13. Hugonnet S, Uçkay I, Pittet D. Staffing level: a determinant of late-onset ventilator-associated pneumonia. Crit Care. 2007;11(4):R80.

14. Valentin A, Capuzzo M, Guidet B, Moreno R, Metnitz B, Bauer P, et al. Research Group on Quality Improvement of the European Society of Intensive Care Medicine (ESICM); Sentinel Events Evaluation (SEE) Study Investigators. Errors in administration of parenteral drugs in intensive care units: multinational prospective study. BMJ. 2009;338:b814.

15. Kim JH, Hong SK, Kim KC, Lee MG, Lee KM, Jung SS, et al. Influence of full-time intensivist and the nurse-to-patient ratio on the implementation of severe sepsis bundles in Korean intensive care units. J Crit Care. 2012;27(4):414.e11-21.

16. Cho SH, Yun SC. Bed-to-nurse ratios, provision of basic nursing care, and in-hospital and 30-day mortality among acute stroke patients admitted to an intensive care unit: cross-sectional analysis of survey and administrative data. Int $\mathbf{J}$ Nurs Stud. 2009;46(8):1092-101. 
17. Chant C, Dewhurst NF, Friedrich JO. Do we need a pharmacist in the ICU? Intensive Care Med. 2015;41(7):1314-20.

18. Engel HJ, Tatebe S, Alonzo PB, Mustille RL, Rivera MJ. Physical therapist-established intensive care unit early mobilization program: quality improvement project for critical care at the University of California San Francisco Medical Center. Phys Ther. 2013;93(7):975-85.

19. Braga JM, Hunt A, Pope J, Molaison E. Implementation of dietitian recommendations for enteral nutrition results in improved outcomes. J Am Diet Assoc. 2006;106(2):281-4.

20. Rimawi RH, Mazer MA, Siraj DS, Gooch M, Cook PP. Impact of regular collaboration between infectious diseases and critical care practitioners on antimicrobial utilization and patient outcome. Crit Care Med. 2013;41(9):2099-107.

21. Pronovost PJ, Angus DC, Dorman T, Robinson KA, Dremsizov TT, Young TL. Physician staffing patterns and clinical outcomes in critically ill patients: a systematic review. JAMA. 2002;288(17):2151-62.

22. Siebig S, Kuhls S, Imhoff M, Langgartner J, Reng M, Schölmerich J, et al. Collection of annotated data in a clinical validation study for alarm algorithms in intensive care-a methodologic framework. J Crit Care. 2010;25(1):128-35.

23. Weiss CH, Moazed F, McEvoy CA, Singer BD, Szleifer I, Amaral LA. Prompting physicians to address a daily checklist and process of care and clinical outcomes: a single-site study. Am J Respir Crit Care Med. 2011;184(6):680-6.

24. Wilcox ME, Adhikari NK. The effect of telemedicine in critically ill patients: systematic review and meta-analysis. Crit Care. 2012;16(4):R127.

25. Berenson RA, Grossman JM, November EA. Does telemonitoring of patients-the eICUimprove intensive care? Health Aff (Millwood). 2009;28(5):w937-47.

26. Chittawatanarat K, Pamorsinlapathum T. The impact of closed ICU model on mortality in general surgical intensive care unit. J Med Assoc Thail. 2009;92(12):1627-34.

27. Topeli A, Laghi F, Tobin MJ. Effect of closed unit policy and appointing an intensivist in a developing country. Crit Care Med. 2005;33(2):299-306.

28. Prayag S. ICUs worldwide: critical care in India. Crit Care. 2002;6(6):479-80.

29. Sherman CB, Carter EJ, Braendli O, Getaneh A, Schluger NW. The East African Training Initiative. A model training program in pulmonary and critical care medicine for low-income countries. Ann Am Thorac Soc. 2016;13(4):451-5.

30. Livianu J, Orlando JM, Giannini A, Terzi RG, Moock M, Marcos C, et al. Organization and staffing of intensive care units in Brazil. Crit Care. 2000;4(1):P219.

31. Du B, Xi X, Chen D, Peng J, China Critical Care Clinical Trial Group (CCCCTG). Clinical review: critical care medicine in mainland China. Crit Care. 2010;14(1):206.

32. Mathivha LR. ICUs worldwide: an overview of critical care medicine in South Africa. Crit Care. 2002;6(1):22-3.

33. Jiang SP, Zheng X, Li X, Lu XY. Effectiveness of pharmaceutical care in an intensive care unit from China. A pre- and post-intervention study. Saudi Med J. 2012;33(7):756-62.

34. Saokaew S, Maphanta S, Thangsomboon P. Impact of pharmacist's interventions on cost of drug therapy in intensive care unit. Pharm Pract (Granada). 2009;7(2):81-7.

35. Aljbouri TM, Alkhawaldeh MS, Abu-Rumman AE, Hasan TA, Khattar HM, Abu-Oliem AS. Impact of clinical pharmacist on cost of drug therapy in the ICU. Saudi Pharm J. 2013;21(4):371-4.

36. Wang T, Benedict N, Olsen KM, Luan R, Zhu X, Zhou N, et al. Effect of critical care pharmacist's intervention on medication errors: a systematic review and meta-analysis of observational studies. J Crit Care. 2015;30(5):1101-6.

37. Hassibian MR, Hassibian S. Telemedicine acceptance and implementation in developing countries: benefits, categories, and barriers. Razavi Int J Med. 2016;4(3).

38. Gupta S, Dewan S, Kaushal A, Seth A, Narula J, Varma A. eICU reduces mortality in STEMI patients in resource-limited areas. Glob Heart. 2014;9(4):425-7.

39. The World Bank. https://data.worldbank.org/indicator/SH.MED.PHYS.ZS?view=chart. Accessed 15 July 2017.

40. Crisp N, Chen L. Global supply of health professionals. N Engl J Med. 2014;370(10):950-7. 
41. Rice B, Periyanayagam U, Chamberlain S, Dreifuss B, Hammerstedt H, Nelson S, et al. Mortality in children under five receiving nonphysician clinician emergency care in Uganda. Pediatrics. 2016;137(3):e20153201.

42. Chamberlain S, Stolz U, Dreifuss B, Nelson SW, Hammerstedt H, Andinda J, et al. Mortality related to acute illness and injury in rural Uganda: task shifting to improve outcomes. PLoS One. 2015;10(4):e0122559.

43. Baker T, Lugazia E, Eriksen J, Mwafongo V, Irestedt L, Konrad D. Emergency and critical care services in Tanzania: a survey of ten hospitals. BMC Health Serv Res. 2013;13:140.

44. Jochberger S, Ismailova F, Lederer W, Mayr VD, Luckner G, Wenzel V, et al. "Helfen Berührt" Study Team. Anesthesia and its allied disciplines in the developing world: a nationwide survey of the Republic of Zambia. Anesth Analg. 2008;106(3):942-8, table of contents.

45. The World Bank. https://data.worldbank.org/indicator/SH.MED.NUMW.P3?view=chart. Accessed 15 July 2017.

46. Munyiginya P, Brysiewicz P, Mill J. Critical care nursing practice and education in Rwanda. Southern African J Crit Care. 2016;32(2):55.

47. Marshall JC, Bosco L, Adhikari NK, Connolly B, Diaz JV, Dorman T, et al. What is an intensive care unit? A report of the task force of the World Federation of Societies of Intensive and Critical Care Medicine. J Crit Care. 2017;37:270-6.

48. Klopotowska JE, Kuiper R, van Kan HJ, de Pont AC, Dijkgraaf MG, Lie-A-Huen L, et al. On-ward participation of a hospital pharmacist in a Dutch intensive care unit reduces prescribing errors and related patient harm: an intervention study. Crit Care. 2010;14(5):R174. https://doi.org/10.1186/cc9278.

49. Riviello ED, Letchford S, Achieng L, Newton MW. Critical care in resource-poor settings: lessons learned and future directions. Crit Care Med. 2011;39(4):860-7.

50. Levine AR, Robertson TE, Papali A, Verceles AC, McCurdy MT. Tele-medicine and point-ofcare ultrasound: a new paradigm for resource-constrained settings. Chest. 2016;149(6):1580-1.

51. Papali A, McCurdy MT, Calvello EJ. A "three delays" model for severe sepsis in resourcelimited countries. J Crit Care. 2015;30(4):861.e9-14.

52. Mock CN, Quansah R, Addae-Mensah L, Donkor P. The development of continuing education for trauma care in an African nation. Injury. 2005;36(6):725-32.

53. Stephens T, De Silva AP, Beane A, Welch J, Sigera C, De Alwis S, et al. Capacity building for critical care training delivery: development and evaluation of the Network for Improving Critical care Skills Training (NICST) programme in Sri Lanka. Intensive Crit Care Nurs. 2017;39:28-36.

54. De Silva AP, Stephens T, Welch J, Sigera C, De Alwis S, Athapattu P, et al. Nursing intensive care skills training: a nurse led, short, structured, and practical training program, developed and tested in a resource-limited setting. J Crit Care. 2015;30(2):438.e7-11.

55. Thunpattu S, Newey V, Sigera C, De Silva P, Goonarathna A, Aluthge I, et al. The effect of a practical ICU workshop on the knowledge, attitudes and skills of physiotherapists in Sri Lanka. https://www.nicslk.com/posters/150330170324physio\%20workshop\%20paper.pdf. Accessed 5 Jan 2017.

56. MacLeod JB, Okech M, Labib M, Aphivantrakul P, Lupasha E, Nthele M. Evaluation of trauma and critical care training courses on the knowledge and confidence of participants in Kenya and Zambia. World J Surg. 2011;35:9-16.

57. Macleod JB, Jones T, Aphivantrakul P, Chupp M, Poenaru D. Evaluation of fundamental critical care course in Kenya: knowledge, attitude, and practice. J Surg Res. 2011;167:223-30.

58. Robertson TE, Levine AR, Verceles AC, Buchner JA, Lantry JH 3rd, Papali A, et al. Remote tele-mentored ultrasound for non-physician learners using FaceTime: a feasibility study in a low-income country. J Crit Care. 2017;40:145-8.

59. Albert TJ, Fassier T, Chhuoy M, Bounchan Y, Tan S, Ku N, et al. Bolstering medical education to enhance critical care capacity in Cambodia. Ann Am Thorac Soc. 2015;12(4):491-7.

60. Haglund MM, Kiryabwire J, Parker S, Zomorodi A, MacLeod D, Schroeder R, et al. Surgical capacity building in Uganda through twinning, technology, and training camps. World J Surg. 2011;35(6):1175-82. 
61. Ulisubisya M, Jörnvall H, Irestedt L, Baker T. Establishing an Anaesthesia and Intensive Care partnership and aiming for national impact in Tanzania. Glob Health. 2016;12:7. https://doi. org/10.1186/s12992-016-0144-1.

62. W/Tsadik A, Azazh A, Teklu S, Seyum N, Geremew H, Rankin P, et al. Development of emergency medicine and critical care masters program for nurses at Addis Ababa University, School of Medicine. Ethiop Med J. 2014;Suppl 2:21-6.

63. BASIC for Developing Healthcare Systems. https://www.aic.cuhk.edu.hk/web8/BASIC\%20 DHS.htm. Accessed 24 July 2017.

64. Joynt GM, Zimmerman J, Li TS, Gomersall CD. A systematic review of short courses for nonspecialist education in intensive care. J Crit Care. 2011;26(5):533.e1-10. https://doi. org/10.1016/j.jcrc.2011.01.007.

65. Belle J, Cohen H, Shindo N, Lim M, Velazquez-Berumen A, Ndihokubwayo JB, et al. Influenza preparedness in low-resource settings: a look at oxygen delivery in 12 African countries. J Infect Dev Ctries. 2010;4(7):419-24.

66. Morrissey B, Conroy N, Estelle A. Effect of solar panels on inpatient paediatric mortality in a district hospital in Sierra Leone (abstract). Arch Dis Child. 2015;100(Suppl 3):A114.

67. Turnbull H, Conroy A, Opoka RO, Namasopo S, Kain KC, Hawkes M. Solar-powered oxygen delivery: proof of concept. Int J Tuberc Lung Dis. 2016;20(5):696-703.

68. WHO model list of essential medicines: 17th list, March 2011. Geneva: World Health Organization; 2011. http://apps.who.int/iris/handle/10665/70640. Accessed 1 Mar 2017.

69. Meara JG, Leather AJ, Hagander L, Alkire BC, Alonso N, Ameh EA, et al. Global Surgery 2030: evidence and solutions for achieving health, welfare, and economic development. Lancet. 2015;386:569-624.

70. Papali A, Verceles AC, Augustin ME, Colas LN, Jean-Francois CH, Patel DM, et al. Sepsis in Haiti: prevalence, treatment, and outcomes in a Port-au-Prince referral hospital. J Crit Care. 2017;38:35-40.

71. Wandi F, Peel D, Duke T. Hypoxaemia among children in rural hospitals in Papua New Guinea: epidemiology and resource availability - a study to support a national oxygen programme. Ann Trop Paediatr. 2006;26(4):277-84.

72. Sutherland T, Musafiri S, Twagirumugabe T, Talmor D, Riviello ED. Oxygen as an essential medicine: under- and over-treatment of hypoxemia in low- and high-income nations. Crit Care Med. 2016;44(10):e1015-6.

73. Foran M, Ahn R, Novik J, Tyer-Viola L, Chilufya K, Katamba K, et al. Prevalence of undiagnosed hypoxemia in adults and children in an under-resourced district hospital in Zambia. Int J Emerg Med. 2010;3(4):351-6.

74. Duke T, Peel D, Wandi F, Subhi R, Sa'avu Martin, Matai S. Oxygen supplies for hospitals in Papua New Guinea: a comparison of the feasibility and cost-effectiveness of methods for different settings. P N G Med J 2010;53(3-4):126-138.

75. Bradley BD, Light JD, Ebonyi AO, N'Jai PC, Ideh RC, Ebruke BE, et al. Implementation and 8-year follow-up of an uninterrupted oxygen supply system in a hospital in The Gambia. Int J Tuberc Lung Dis. 2016;20(8):1130-4.

76. Peel D, Howie SRC. Oxygen concentrators for use in tropical countries: a survey. J Clin Eng. 2009;34(4):205-9.

77. Howie SR, Hill S, Ebonyi A, Krishnan G, Njie O, Sanneh M, et al. Meeting oxygen needs in Africa: an options analysis from the Gambia. Bull World Health Organ. 2009;87(10):763-71.

78. http://freewestmedia.com/2016/12/29/south-africas-copper-thieves-putting-lives-at-risk/. Accessed 17 Aug 2017.

79. Duke T, Wandi F, Jonathan M, Matai S, Kaupa M, Saavu M, et al. Improved oxygen systems for childhood pneumonia: a multihospital effectiveness study in Papua New Guinea. Lancet. 2008;372(9646):1328-33.

80. Pittet D, Donaldson L. Clean care is safer care: the first global challenge of the WHO world alliance for patient safety. Infect Control Hosp Epidemiol. 2005;26(11):891-4. 
81. Allegranzi B, Nejad SB, Combescure C, Graafmans W, Attar H, Donaldson L, et al. Burden of endemic health-care-associated infection in developing countries: systematic review and meta-analysis. Lancet. 2011;377:228-41.

82. Wasswa P, Nalwadda CK, Buregyeya E, Gitta SN, Anguzu P, Nuwaha F. Implementation of infection control in health facilities in Arua district, Uganda: a cross-sectional study. BMC Infect Dis. 2015;15:268.

83. Horng LM, Unicomb L, Alam MU, Halder AK, Shoab AK, Ghosh PK, et al. Healthcare worker and family caregiver hand hygiene in Bangladeshi healthcare facilities: results from the Bangladesh National Hygiene Baseline Survey. J Hosp Infect. 2016;94(3):286-94.

84. World Health Organization. 2009: WHO guidelines on hand hygiene in health care: a summary first global patient safety challenge clean care is safer care. 2009. http://www.who.int/ gpsc/5may/tools/9789241597906/en/. Accessed 3 May 2017.

85. Rosenthal VD, Pawar M, Leblebicioglu H, Navoa-Ng JA, Villamil-Gómez W, Armas-Ruiz A, et al. Impact of the International Nosocomial Infection Control Consortium (INICC) multidimensional hand hygiene approach over 13 years in 51 cities of 19 limited-resource countries from Latin America, Asia, the Middle East, and Europe. Infect Control Hosp Epidemiol. 2013;34(4):415-23.

86. Chakravarthy M, Myatra SN, Rosenthal VD, Udwadia FE, Gokul BN, Divatia JV, et al. The impact of the International Nosocomial Infection Control Consortium (INICC) multicenter, multidimensional hand hygiene approach in two cities of India. J Infect Public Health. 2015;8(2):177-86.

87. Su D, Hu B, Rosenthal VD, Li R, Hao C, Pan W, et al. Impact of the International Nosocomial Infection Control Consortium (INICC) Multidimensional Hand Hygiene Approach in five intensive care units in three cities of China. Public Health. 2015;129(7):979-88.

88. Miranda-Novales MG, Sobreyra-Oropeza M, Rosenthal VD, Higuera F, Armas-Ruiz A, Pérez-Serrato I, et al. Impact of the International Nosocomial Infection Control Consortium (INICC) multidimensional hand hygiene approach during 3 years in 6 hospitals in 3 Mexican cities. J Patient Saf. 2015.

89. Barrera L, Zingg W, Mendez F, Pittet D. Effectiveness of a hand hygiene promotion strategy using alcohol-based handrub in 6 intensive care units in Colombia. Am J Infect Control. 2011;39:633-9.

90. Abaza AF, Amine AE, Hazzah WA. Comparative study on efficacy of different alcohol hand rubs and routine hand wash in a health-care setting, Alexandria, Egypt. J Egypt Public Health Assoc. 2010;85(5-6):273-83.

91. Girou E, Loyeau S, Legrand P, Oppein F, Brun-Buisson C. Efficacy of handrubbing with alcohol based solution versus standard handwashing with antiseptic soap: randomised clinical trial. BMJ. 2002;325(7360):362.

92. Poliquin PG, Vogt F, Kasztura M, Leung A, Deschambault Y, Van den Bergh R, et al. Environmental contamination and persistence of Ebola virus RNA in an Ebola treatment center. J Infect Dis. 2016;214(suppl 3):S145-52.

93. Wolfe MK, Wells E, Mitro B, Desmarais AM, Scheinman P, Lantagne D. Seeking clearer recommendations for hand hygiene in communities facing Ebola: a randomized trial investigating the impact of six hand washing methods on skin irritation and dermatitis. PLoS One. 2016;11(12):e0167378. https://doi.org/10.1371/journal.pone.0167378.

94. Rossoff LJ, Lam S, Hilton E, Borenstein M, Isenberg HD. Is the use of boxed gloves in an intensive care unit safe? Am J Med. 1993;94(6):602-7.

95. Luckey JB, Barfield RD, Eleazer PD. Bacterial count comparisons on examination gloves from freshly opened boxes versus nearly empty boxes and from examination gloves before treatment versus after dental dam isolation. J Endod. 2006;32(7):646-8.

96. Rock C, Harris AD, Reich NG, Johnson JK, Thom KA. Is hand hygiene before putting on nonsterile gloves in the intensive care unit a waste of healthcare worker time? - a randomized controlled trial. Am J Infect Control. 2013;41(11):994-6.

97. Diaz MH, Silkaitis C, Malczynski M, Noskin GA, Warren JR, Zembower T. Contamination of examination gloves in patient rooms and implications for transmission of antimicrobialresistant microorganisms. Infect Control Hosp Epidemiol. 2008;29(1):63-5. 
98. Popp W, Rasslan O, Unahalekhaka A, Brenner P, Fischnaller E, Fathy M, et al. What is the use? An international look at reuse of single-use medical devices. Int J Hyg Environ Health. 2010;213(4):302-7. https://doi.org/10.1016/j.ijheh.2010.04.003. Epub 2010 May 13.

99. Hagos B, Kibwage IO, Mwongera M, Muthotho JN, Githiga IM, Mukindia GG. The microbial and physical quality of recycled gloves. East Afr Med J. 1997;74(4):224-6.

100. Ali Z, Qadeer A, Akhtar A. To determine the effect of wearing shoe covers by medical staff and visitors on infection rates, mortality and length of stay in Intensive Care Unit. Pak J Med Sci. 2014;30(2):272-5.

101. Daschner F, Frank U, Just HM. Proven and unproven methods in hospital infection control in intensive care units. Chemioterapia. 1987;6(3):184-9.

102. Croft LD, Harris AD, Pineles L, Langenberg P, Shardell M, Fink JC, et al. Benefits of Universal Glove and Gown Primary Investigators. The effect of universal glove and gown use on adverse events in intensive care unit patients. Clin Infect Dis. 2015;61(4):545-53. https:// doi.org/10.1093/cid/civ315.

103. Harris AD, Pineles L, Belton B, Johnson JK, Shardell M, Loeb M, Newhouse R, et al. Universal glove and gown use and acquisition of antibiotic-resistant bacteria in the ICU: a randomized trial. JAMA. 2013;310(15):1571-80.

104. Huskins WC, Huckabee CM, O’Grady NP, Murray P, Kopetskie H, Zimmer L, et al. Intervention to reduce transmission of resistant bacteria in intensive care. $\mathrm{N}$ Engl $\mathrm{J}$ Med. 2011;364(15):1407-18.

105. Webster $\mathbf{J}$ and Pritchard MA. Gowning by attendants and visitors in newborn nurseries for prevention of neonatal morbidity and mortality. Cochrane Database Syst Rev 2003;(3):CD003670.

106. Mehta Y, Gupta A, Todi S, Myatra SN, Samaddar DP, Vijaya P, et al. Guidelines for prevention of hospital acquired infections. Indian J Crit Care Med. 2014;18(3):149-63.

107. World Health Organization. Guidelines on core components of infection prevention and control programmes at the national and acute health care facility level. http://www.who.int/gpsc/ ipc-components-guidelines/en/. Accessed 22 Aug 2017.

108. Smith JD, MacDougall CC, Johnstone J, Copes RA, Schwartz B, Garber GE. Effectiveness of N95 respirators versus surgical masks in protecting health care workers from acute respiratory infection: a systematic review and meta-analysis. CMAJ. 2016;188(8):567-74.

109. Jefferson T, Del Mar CB, Dooley L, Ferroni E, Al-Ansary LA, Bawazeer GA, et al. Physical interventions to interrupt or reduce the spread of respiratory viruses. Cochrane Database Syst Rev. 2011;(7):CD006207.

110. Loeb M, Dafoe N, Mahony J, John M, Sarabia A, Glavin V, et al. Surgical mask vs N95 respirator for preventing influenza among health care workers: a randomized trial. JAMA. 2009;302(17):1865-71.

111. Centers for Disease Control and Prevention. Guideline for isolation precautions: preventing transmission of infectious agents in healthcare settings. 2007. https://www.cdc.gov/infectioncontrol/guidelines/isolation/index.html. Accessed 21 May 2017.

112. World Health Organization. Personal protective equipment for use in a filovirus disease outbreak: rapid advice guideline. 2016. https://www.ncbi.nlm.nih.gov/books/NBK401170/. Accessed 21 May 2017.

113. Pronovost P, Needham D, Berenholtz S, Sinopoli D, Chu H, Cosgrove S, et al. An intervention to decrease catheter-related bloodstream infections in the ICU. N Engl J Med. 2006;355(26):2725-32.

114. Latif A, Kelly B, Edrees H, Kent PS, Weaver SJ, Jovanovic B, et al. Implementing a multifaceted intervention to decrease central line-associated bloodstream infections in SEHA (Abu Dhabi Health Services Company) intensive care units: the Abu Dhabi experience. Infect Control Hosp Epidemiol. 2015;36(7):816-22.

115. Marsteller JA, Sexton JB, Hsu YJ, Hsiao CJ, Holzmueller CG, Pronovost PJ, et al. A multicenter, phased, cluster-randomized controlled trial to reduce central line-associated bloodstream infections in intensive care units*. Crit Care Med. 2012;40(11):2933-9. 
116. Lin DM, Weeks K, Bauer L, Combes JR, George CT, Goeschel CA, et al. Eradicating central line-associated bloodstream infections statewide: the Hawaii experience. Am J Med Qual. 2012;27(2):124-9.

117. Hong AL, Sawyer MD, Shore A, Winters BD, Masuga M, Lee H, et al. Decreasing centralline-associated bloodstream infections in Connecticut intensive care units. J Healthc Qual. 2013;35(5):78-87.

118. Sagana R, Hyzy RC. Achieving zero central line-associated bloodstream infection rates in your intensive care unit. Crit Care Clin. 2013;29(1):1-9.

119. Dettenkofer M, Seegers S, Antes G, Motschall E, Schumacher M, Daschner FD. Does the architecture of hospital facilities influence nosocomial infection rates? A systematic review. Infect Control Hosp Epidemiol. 2004;25(1):21-5.

120. Cepeda JA, Whitehouse T, Cooper B, Hails J, Jones K, Kwaku F, et al. Isolation of patients in single rooms or cohorts to reduce spread of MRSA in intensive-care units: prospective twocentre study. Lancet. 2005;365(9456):295-304.

121. Leaf DE, Homel P, Factor PH. Relationship between ICU design and mortality. Chest. 2010;137(5):1022-7.

122. Arabi YM, Phua J, Koh Y, Du B, Faruq MO, Nishimura M, et al; Asian Critical Care Clinical Trials Group. Structure, organization, and delivery of critical care in Asian ICUs. Crit Care Med 2016;44(10):e940-8.

123. Escombe AR, Moore DA, Gilman RH, Navincopa M, Ticona E, Mitchell B, et al. Upper room ultraviolet light and negative air ionization to prevent tuberculosis transmission. PLoS Med. 2009;6(3):e43.

124. Mphaphlele M, Dharmadhikari AS, Jensen PA, Rudnick SN, van Reenen TH, Pagano MA, et al. Institutional Tuberculosis Transmission. Controlled trial of upper room ultraviolet air disinfection: a basis for new dosing guidelines. Am J Respir Crit Care Med. 2015;192(4):477-84.

125. Mehta Y, Gupta A, Todi S, Myatra S, Samaddar DP, Patil V, et al. Guidelines for prevention of hospital acquired infections. Indian J Crit Care Med. 2014;18(3):149-63.

126. World Health Organization. Guide to local production: WHO-recommended handrub formulations. http://www.who.int/gpsc/5may/Guide_to_Local_Production.pdf. Accessed 16 Aug 2017.

127. Iqbal Q, Lubeck-Schricker M, Wells E, Wolfe MK, Lantagne D. Shelf-life of chlorine solutions recommended in Ebola virus disease response. PLoS One. 2016;11(5):e0156136. https://doi.org/10.1371/journal.pone.0156136.

128. Thi Anh Thu L, Thi Hong Thoa V, Thi Van Trang D, Phuc Tien N, Thuy Van D, Thi Kim Anh L, et al. Cost-effectiveness of a hand hygiene program on health care-associated infections in intensive care patients at a tertiary care hospital in Vietnam. Am J Infect Control. 2015;43(12):e93-9.

129. Nthumba PM, Stepita-Poenaru E, Poenaru D, Bird P, Allegranzi B, Pittet D, et al. Cluster-randomized, crossover trial of the efficacy of plain soap and water versus alcohol-based rub for surgical hand preparation in a rural hospital in Kenya. Br J Surg. 2010;97(11):1621-8.

130. Ahmed QA, Memish ZA, Allegranzi B, Pittet D. Muslim health-care workers and alcoholbased handrubs. Lancet. 2006;367(9515):1025-7.

131. Chughtai AA, Seale H, Chi Dung T, Maher L, Nga PT, MacIntyre CR. Current practices and barriers to the use of facemasks and respirators among hospital-based health care workers in Vietnam. Am J Infect Control. 2015;43(1):72-7. https://doi.org/10.1016/j. ajic.2014.10.009.

132. MacIntyre CR, Seale H, Dung TC, Hien NT, Nga PT, Chughtai AA, et al. A cluster randomised trial of cloth masks compared with medical masks in healthcare workers. BMJ Open. 2015;5(4):e006577.

133. World Health Organization. Infection prevention and control (IPC) guidance summary: Ebola guidance package. http://www.who.int//csr/disease/ebola/evid-guidance-summary/en/. Accessed 17 Aug 2017. 
134. Lilford RJ, Burn SL, Diaconu KD, Lilford P, Chilton PJ, Bion V, et al. An approach to prioritization of medical devices in low-income countries: an example based on the Republic of South Sudan. Cost Eff Resour Alloc. 2015;13(1):2.

135. Bauserman M, Hailey C, Gado J, Lokangaka A, Williams J, Richards-Kortum R, et al. Determining the utility and durability of medical equipment donated to a rural clinic in a low-income country. Int Health. 2015;7(4):262-5.

136. Clarke DL, Chipps JA, Sartorius B, Bruce J, Laing GL, Brysiewicz P. Mortality rates increase dramatically below a systolic blood pressure of $105-\mathrm{mm} \mathrm{Hg}$ in septic surgical patients. Am J Surg. 2016;212(5):941-5.

137. Dünser MW, Ruokonen E, Pettilä V, Ulmer H, Torgersen C, Schmittinger CA, et al. Association of arterial blood pressure and vasopressor load with septic shock mortality: a post hoc analysis of a multicenter trial. Crit Care. 2009;13(6):R181.

138. Vellinga NA, Boerma EC, Koopmans M, Donati A, Dubin A, Shapiro N, et al. International study on microcirculatory shock occurrence in acutely ill patients. Crit Care Med. 2015;43(1):48-56.

139. Seymour CW, Liu VX, Iwashyna TJ, Brunkhorst FM, Rea TD, Scherag A, et al. Assessment of clinical criteria for sepsis: for the third international consensus definitions for sepsis and septic shock (Sepsis-3). JAMA. 2016;315(8):762-74.

140. Riviello ED, Buregeya E, Twagirumugabe T. Diagnosing acute respiratory distress syndrome in resource limited settings: the Kigali modification of the Berlin definition. Curr Opin Crit Care. 2017;23(1):18-23.

141. Lazzerini M, Sonego M, Pellegrin MC. Hypoxaemia as a mortality risk factor in acute lower respiratory infections in children in low and middle-income countries: systematic review and meta-analysis. PLoS One. 2015;10(9):e0136166.

142. Orimadegun AE, Ogunbosi BO, Carson SS. Prevalence and predictors of hypoxaemia in respiratory and non-respiratory primary diagnoses among emergently ill children at a tertiary hospital in south western Nigeria. Trans R Soc Trop Med Hyg. 2013;107(11):699-705.

143. Baker T, Blixt J, Lugazia E, Schell CO, Mulungu M, Milton A, et al. Single deranged physiologic parameters are associated with mortality in a low-income country. Crit Care Med. 2015;43(10):2171-9.

144. Schell CO, Castegren M, Lugazia E, Blixt J, Mulungu M, Konrad D, et al. Severely deranged vital signs as triggers for acute treatment modifications on an intensive care unit in a lowincome country. BMC Res Notes. 2015;8:313.

145. Waitt PI, Mukaka M, Goodson P, SimuKonda FD, Waitt CJ, Feasey N, et al. Sepsis carries a high mortality among hospitalised adults in Malawi in the era of antiretroviral therapy scaleup: a longitudinal cohort study. J Infect. 2015;70(1):11-9.

146. Thanachartwet V, Wattanathum A, Sahassananda D, Wacharasint P, Chamnanchanunt S, Khine Kyaw E, et al. Dynamic measurement of hemodynamic parameters and cardiac preload in adults with dengue: a prospective observational study. PLoS One. 2016;11(5):e0156135.

147. Baker T, Schell CO, Lugazia E, Blixt J, Mulungu M, Castegren M, et al. Vital signs directed therapy: improving care in an intensive care unit in a low-income country. PLoS One. 2015;10(12):e0144801.

148. Bur A, Hirschl MM, Herkner H, Oschatz E, Kofler J, Woisetschläger C, et al. Accuracy of oscillometric blood pressure measurement according to the relation between cuff size and upper-arm circumference in critically ill patients. Crit Care Med. 2000;28(2):371-6.

149. Lakhal K, Ehrmann S, Runge I, Legras A, Dequin PF, Mercier E, et al. Tracking hypotension and dynamic changes in arterial blood pressure with brachial cuff measurements. Anesth Analg. 2009;109(2):494-501.

150. Chatterjee A, DePriest K, Blair R, Bowton D, Chin R. Results of a survey of blood pressure monitoring by intensivists in critically ill patients: a preliminary study. Crit Care Med. 2010;38(12):2335-8.

151. Pedersen T, Nicholson A, Hovhannisyan K, Møller AM, Smith AF, Lewis SR. Pulse oximetry for perioperative monitoring. Cochrane Database Syst Rev. 2014;(3):CD002013. 
152. Serpa Neto A, Cardoso SO, Ong DS, Espósito DC, Pereira VG, Manetta JA, et al. The use of the pulse oximetric saturation/fraction of inspired oxygen ratio for risk stratification of patients with severe sepsis and septic shock. J Crit Care. 2013;28(5):681-6.

153. Serpa Neto A, Schultz MJ, Festic E. Ventilatory support of patients with sepsis or septic shock in resource-limited settings. Intensive Care Med. 2016;42(1):100-3.

154. Becker DM, Tafoya CA, Becker SL, Kruger GH, Tafoya MJ, Becker TK. The use of portable ultrasound devices in low- and middle-income countries: a systematic review of the literature. Tropical Med Int Health. 2016;21(3):294-311.

155. Thwaites CL, Yen LM, Nga NT, Parry J, Binh NT, Loan HT, et al. Impact of improved vaccination programme and intensive care facilities on incidence and outcome of tetanus in southern Vietnam, 1993-2002. Trans R Soc Trop Med Hyg. 2004;98(11):671-7.

156. Trieu HT, Lubis IN, Qui PT, Yen LM, Wills B, Thwaites CL, Sabanathan S. Neonatal tetanus in Vietnam: comprehensive intensive care support improves mortality. J Pediatric Infect Dis Soc. 2016;5(2):227-30. https://doi.org/10.1093/jpids/piv059.

157. Haniffa R, Lubell Y, Cooper BS, Mohanty S, Alam S, Karki A, et al. Impact of a structured ICU training programme in resource-limited settings in Asia. PLoS One. 2017;12(3):e0173483.

158. Balfour-Lynn RE, Marsh G, Gorayi D, Elahi E, LaRovere J. Non-invasive ventilation for children with acute respiratory failure in the developing world: literature review and an implementation example. Paediatr Respir Rev. 2014;15(2):181-7.

159. Verma AK, Mishra M, Kant S, Kumar A, Verma SK, Chaudhri S, et al. Noninvasive mechanical ventilation: an 18-month experience of two tertiary care hospitals in north India. Lung India. 2013;30(4):307-11.

160. Wilson PT, Morris MC, Biagas KV, Otupiri E, Moresky RT. A randomized clinical trial evaluating nasal continuous positive airway pressure for acute respiratory distress in a developing country. J Pediatr. 2013;162(5):988-92.

161. Chisti MJ, Salam MA, Smith JH, Ahmed T, Pietroni MA, Shahunja KM, et al. Bubble continuous positive airway pressure for children with severe pneumonia and hypoxaemia in Bangladesh: an open, randomised controlled trial. Lancet. 2015;386(9998):1057-65.

162. Jayashree M, KiranBabu HB, Singhi S, Nallasamy K. Use of nasal bubble CPAP in children with hypoxemic clinical pneumonia-report from a resource limited set-up. J Trop Pediatr. 2016;62(1):69-74.

163. Kawaza K, Machen HE, Brown J, Mwanza Z, Iniguez S, Gest A, et al. Efficacy of a lowcost bubble CPAP system in treatment of respiratory distress in a neonatal ward in Malawi. Malawi Med J. 2016;28(3):131-7.

164. Langhan M. Continuous end-tidal carbon dioxide monitoring in pediatric intensive care units. J Crit Care. 2009;24(2):227-30.

165. Erasmus PD. The use of end-tidal carbon dioxide monitoring to confirm endotracheal tube placement in adult and paediatric intensive care units in Australia and New Zealand. Anaesth Intensive Care. 2004;32(5):672-5.

166. Ginosar Y, Shapira SC. The role of an anaesthetist in a field hospital during the cholera epidemic among Rwandan refugees in Goma. Br J Anaesth. 1995;75(6):810-6.

167. Husaini J, Choy YC. End-tidal to arterial carbon dioxide partial pressure difference during craniotomy in anaesthetised patients. Med J Malaysia. 2008;63(5):384-7.

168. Prause G, Hetz H, Lauda P, Pojer H, Smolle-Juettner F, Smolle J. A comparison of the end-tidal- $\mathrm{CO}_{2}$ documented by capnometry and the arterial $\mathrm{pCO}_{2}$ in emergency patients. Resuscitation. 1997;35(2):145-8.

169. Totapally BR. Utility of end-tidal carbon dioxide monitoring in critically ill children. Indian J Crit Care Med. 2014;18(6):341-2.

170. Thrush DN, Mentis SW, Downs JB. Weaning with end-tidal $\mathrm{CO}_{2}$ and pulse oximetry. J Clin Anesth. 1991;3(6):456-60.

171. Healey CJ, Fedullo AJ, Swinburne AJ, Wahl GW. Comparison of noninvasive measurements of carbon dioxide tension during withdrawal from mechanical ventilation. Crit Care Med. 1987;15(8):764-8. 
172. Bluemile LW Jr, Webster GD Jr, Elkinton JR. Acute tubular necrosis; analysis of one hundred cases with respect to mortality, complications, and treatment with and without dialysis. AMA Arch Intern Med. 1959;104(2):180-97.

173. Arogundade FA, Sanusi AA, Okunola OO, Soyinka FO, Ojo OE, Akinsola A. Acute renal failure (ARF) in developing countries: which factors actually influence survival. Cent Afr J Med. 2007;53(5-8):34-9.

174. Mer M, Schultz MJ, Adhikari NK (2017) European Society of Intensive Care Medicine (ESICM) Global Intensive Care Working Group and the Mahidol-Oxford Research Unit (MORU), Bangkok, Thailand Core elements of general supportive care for patients with sepsis and septic shock in resource-limited settings Intensive Care Med. https://doi.org/10.1007/ s00134-017-4831-z.

175. Park S, Kim DG, Suh GY, Kang JG, Ju YS, Lee YJ, et al. Mild hypoglycemia is independently associated with increased risk of mortality in patients with sepsis: a 3-year retrospective observational study. Crit Care. 2012;16(5):R189.

176. Bagshaw SM, Bellomo R, Jacka MJ, Egi M, Hart GK, George C. The impact of early hypoglycemia and blood glucose variability on outcome in critical illness. Crit Care. 2009;13(3):R91.

177. Casserly B, Phillips GS, Schorr C, Dellinger RP, Townsend SR, Osborn TM, et al. Lactate measurements in sepsis-induced tissue hypoperfusion: results from the Surviving Sepsis Campaign database. Crit Care Med. 43(3):567-73.

178. Mikkelsen ME, Miltiades AN, Gaieski DF, Goyal M, Fuchs BD, Shah CV, et al. Serum lactate is associated with mortality in severe sepsis independent of organ failure and shock. Crit Care Med. 2009;37(5):1670-7.

179. Nguyen HB, Rivers EP, Knoblich BP, Jacobsen G, Muzzin A, Ressler JA, et al. Early lactate clearance is associated with improved outcome in severe sepsis and septic shock. Crit Care Med. 2004;32(8):1637-42.

180. Moore CC, Jacob ST, Pinkerton R, Meya DB, Mayanja-Kizza H, Reynolds SJ, et al. Point-ofcare lactate testing predicts mortality of severe sepsis in a predominantly HIV type 1-infected patient population in Uganda. Clin Infect Dis. 2008;46(2):215-22.

181. Mtove G, Nadjm B, Hendriksen IC, Amos B, Muro F, Todd J, et al. Point-of-care measurement of blood lactate in children admitted with febrile illness to an African District Hospital. Clin Infect Dis. 2011;53(6):548-54.

182. Krishna S, Waller DW, ter Kuile F, Kwiatkowski D, Crawley J, Craddock CF, Nosten F, et al. Lactic acidosis and hypoglycaemia in children with severe malaria: pathophysiological and prognostic significance. Trans R Soc Trop Med Hyg. 1994;88:67-73.

183. Molyneux ME, Taylor TE, Wirima JJ, Borgstein A. Clinical features and prognostic indicators in paediatric cerebral malaria: a study of 131 comatose Malawian children. Q J Med. 1989;71:441-59.

184. Subbarao S, Wilkinson KA, van Halsema CL, Rao SS, Boyles T, Utay NS, et al. Raised venous lactate and markers of intestinal translocation are associated with mortality among in-patients with HIV-associated TB in Rural South Africa. J Acquir Immune Defic Syndr. 2015;70(4):406-13.

185. Krishna U, Joshi SP, Modh M. An evaluation of serial blood lactate measurement as an early predictor of shock and its outcome in patients of trauma or sepsis. Indian J Crit Care Med. 2009;13(2):66-73.

186. Ssekitoleko R, Jacob ST, Banura P, Pinkerton R, Meya DB, Reynolds SJ, et al. Hypoglycemia at admission is associated with in hospital mortality in Ugandan patients with severe sepsis. Crit Care Med. 2011;39(10):2271-6.

187. Jallow M, Casals-Pascual C, Ackerman H, Walther B, Walther M, Pinder M, et al. Clinical features of severe malaria associated with death: a 13-year observational study in the Gambia. PLoS One. 2012;7(9):e45645.

188. Jones KL, Donegan S, Lalloo DG. Artesunate versus quinine for treating severe malaria. Cochrane Database Syst Rev. 2007;(4):CD005967. 
189. Ramachandran B, Sethuraman R, Ravikumar KG, Kissoon N. Comparison of bedside and laboratory blood glucose estimations in critically ill children with shock. Pediatr Crit Care Med. 2011;12(6):e297-301.

190. Hawkes M, Conroy AL, Opoka RO, Namasopo S, Liles WC, John CC, et al. Performance of point-of-care diagnostics for glucose, lactate, and hemoglobin in the management of severe malaria in a resource-constrained hospital in Uganda. Am J Trop Med Hyg. 2014;90(4):605-8.

191. Meynaar IA, van Spreuwel M, Tangkau PL, Dawson L, Sleeswijk Visser S, Rijks L, et al. Accuracy of AccuChek glucose measurement in intensive care patients. Crit Care Med. 2009;37(10):2691-6.

192. DuBois JA, Slingerland RJ, Fokkert M, Roman A, Tran NK, Clarke W, et al. Bedside glucose monitoring-is it safe? A new, regulatory-compliant risk assessment evaluation protocol in critically ill patient care settings. Crit Care Med. 2017;45(4):567-74.

193. Gu WJ, Zhang Z, Bakker J. Early lactate clearance-guided therapy in patients with sepsis: a meta-analysis with trial sequential analysis of randomized controlled trials. Intensive Care Med. 2015;41(10):1862-3.

194. Burri E, Potocki M, Drexler B, Schuetz P, Mebazaa A, Ahlfeld U, et al. Value of arterial blood gas analysis in patients with acute dyspnea: an observational study. Crit Care. 2011;15(3):R145. https://doi.org/10.1186/cc10268.

195. ARDS Definition Task Force, Ranieri VM, Rubenfeld GD, Thompson BT, Ferguson ND, Caldwell E, Fan E, et al. Acute respiratory distress syndrome: the Berlin Definition. JAMA. 2012;307(23):2526-33. https://doi.org/10.1001/jama.2012.5669.

196. Chawla R, Mansuriya J, Modi N, Pandey A, Juneja D, Chawla A, et al. Acute respiratory distress syndrome: Predictors of noninvasive ventilation failure and intensive care unit mortality in clinical practice. J Crit Care. 2016;31(1):26-30. https://doi.org/10.1016/j.jcrc.2015.10.018.

197. Chittawatanarat K, Morakul S, Thawitsri T. Non-cardiopulmonary monitoring in Thai-ICU (ICU-Resource I study). J Med Assoc Thail. 2014;97(Suppl 1):S31-7.

198. Chittawatanarat K, Wattanathum A, Chaiwat O. Cardiopulmonary monitoring in Thai ICUs (ICU-resource I study). J Med Assoc Thail. 2014;97(Suppl 1):S15-21.

199. Chittawatanarat K, Bunburaphong T, Champunot R. Mechanical ventilators availability survey in Thai ICUs (ICU-resource I study). J Med Assoc Thail. 2014;97 Suppl 1:S1-7.

200. LeBrun DG, Chackungal S, Chao TE, Knowlton LM, Linden AF, Notrica MR, et al. Prioritizing essential surgery and safe anesthesia for the Post 2015 Development Agenda: operative capacities of 78 district hospitals in 7 low- and middle-income countries. Surgery. 2014;155(3):365-73.

201. Bataar O, Lundeg G, Tsenddorj G, Jochberger S, Grander W, Baelani I, et al. Nationwide survey on resource availability for implementing current sepsis guidelines in Mongolia. Bull World Health Organ. 2010;88(11):839-46.

202. Baelani I, Jochberger S, Laimer T, Otieno D, Kabutu J, Wilson I, et al. Availability of critical care resources to treat patients with severe sepsis or septic shock in Africa: a self-reported, continent-wide survey of anaesthesia providers. Crit Care. 2011;15(1):R10.

203. Baelani I, Jochberger S, Laimer T, Rex C, Baker T, Wilson IH, et al. Identifying resource needs for sepsis care and guideline implementation in the Democratic Republic of the Congo: a cluster survey of 66 hospitals in four eastern provinces. Middle East J Anaesthesiol. 2012;21(4):559-75.

204. Mendsaikhan N, Gombo D, Lundeg G, Schmittinger C, Dünser MW. Management of potentially life-threatening emergencies at 74 primary level hospitals in Mongolia: results of a prospective, observational multicenter study. BMC Emerg Med. 2017;17(1):15.

205. Mendsaikhan N, Begzjav T, Lundeg G, Brunauer A, Dünser MW. A Nationwide Census of ICU Capacity and Admissions in Mongolia. PLoS One. 2016;11(8):e0160921.

206. Liyanage T, Ninomiya T, Jha V, Neal B, Patrice HM, Okpechi I, et al. Worldwide access to treatment for end-stage kidney disease: a systematic review. Lancet. 2015;385(9981):1975-82. 
207. Gatrad AR, Gatrad S, Gatrad A. Equipment donation to developing countries. Anaesthesia. 2007;62 Suppl 1:90-95.

208. Burn SL, Chilton PJ, Gawande AA, Lilford RJ. Peri-operative pulse oximetry in low-income countries: a cost-effectiveness analysis. Bull World Health Organ. 2014;92(12):858-67.

209. Chen A, Deshmukh AA, Richards-Kortum R, Molyneux E, Kawaza K, Cantor SB. Costeffectiveness analysis of a low-cost bubble CPAP device in providing ventilatory support for neonates in Malawi-a preliminary report. BMC Pediatr. 2014;14:288.

210. Patel SP, Pena ME, Babcock CI. Cost-effectiveness of noninvasive ventilation for chronic obstructive pulmonary disease-related respiratory failure in Indian hospitals without ICU facilities. Lung India. 2015;32(6):549-56.

211. Poesen K, De Prins M, Van den Berghe G, Van Eldere J, Vanstapel F. Performance of cassettebased blood gas analyzers to monitor blood glucose and lactate levels in a surgical intensive care setting. Clin Chem Lab Med. 2013;51(7):1417-27.

212. Singh S, Bhardawaj A, Shukla R, Jhadav T, Sharma A, Basannar D. The handheld blood lactate analyser versus the blood gas based analyser for measurement of serum lactate and its prognostic significance in severe sepsis. Med J Armed Forces India. 2016;72(4):325-31.

213. Dat VQ, Long NT, Giang KB, Diep PB, Giang TH, Diaz JV. Healthcare infrastructure capacity to respond to severe acute respiratory infection (SARI) and sepsis in Vietnam: a low-middle income country. J Crit Care. 2017;42:109-15. https://doi.org/10.1016/j.jcrc.2017.07.020.

214. Chen W, Janz DR, Shaver CM, Bernard GR, Bastarache JA, Ware LB. Clinical characteristics and outcomes are similar in ARDS diagnosed by oxygen saturation/ $/ \mathrm{FiO}_{2}$ ratio compared with $\mathrm{PaO}_{2} / \mathrm{FiO}_{2}$ ratio. Chest. 2015;148(6):1477-83. https://doi.org/10.1378/chest.15-0169.

215. Vukoja M, Riviello E, Gavrilovic S, Adhikari NK, Kashyap R, Bhagwanjee S. A survey on critical care resources and practices in low- and middle-income countries. Glob Heart. 2014;9(3):337-42.e1-5.

216. Schultz MJ, Dunser MW, Dondorp AM, Adhikari NK, Iyer S, Kwizera A, et al. Current challenges in the management of sepsis in ICUs in resource-poor settings and suggestions for the future. Intensive Care Med. 2017;43(5):612-24.

217. Thompson G, O'Horo JC, Pickering BW, Herasevich V. Impact of the electronic medical record on mortality, length of stay, and cost in the hospital and ICU: a systematic review and metaanalysis. Crit Care Med. 2015;43(6):1276-82.

218. Pronovost P, Berenholtz S, Dorman T, Lipsett PA, Simmonds T, Haraden C. Improving communication in the ICU using daily goals. J Crit Care. 2003;18(2):71-5.

219. Narasimhan M, Eisen LA, Mahoney CD, Acerra FL, Rosen MJ. Improving nurse-physician communication and satisfaction in the intensive care unit with a daily goals worksheet. Am J Crit Care. 2006;15(2):217-22.

220. Agarwal S, Frankel L, Tourner S, McMillan A, Sharek PJ. Improving communication in a pediatric intensive care unit using daily patient goal sheets. J Crit Care. 2008;23(2):227-35.

221. Centofanti JE, Duan EH, Hoad NC, Swinton ME, Perri D, Waugh L, et al. Use of a daily goals checklist for morning ICU rounds: a mixed-methods study. Crit Care Med. 2014;42(8):1797-803.

222. Perry V, Christiansen M, Simmons A. A daily goals tool to facilitate indirect nursephysician communication during morning rounds on a medical-surgical unit. Medsurg Nurs. 2016;25(2):83-7.

223. Cavalcanti AB, Bozza FA, Machado FR, Salluh JI, Campagnucci VP, Vendramim P, et al. Effect of a quality improvement intervention with daily round checklists, goal setting, and clinician prompting on mortality of critically ill patients: a randomized clinical trial. JAMA. 2016;315(14):1480-90.

224. Ferrer R, Artigas A, Levy MM, Blanco J, González-Díaz G, Garnacho-Montero J, et al. Improvement in process of care and outcome after a multicenter severe sepsis educational program in Spain. JAMA. 2008;299(19):2294-303.

225. Barochia AV, Cui X, Vitberg D, Suffredini AF, O'Grady NP, Banks SM, et al. Bundled care for septic shock: an analysis of clinical trials. Crit Care Med. 2010;38(2):668-78. 
226. Wang Z, Xiong Y, Schorr C, Dellinger RP. Impact of sepsis bundle strategy on outcomes of patients suffering from severe sepsis and septic shock in china. J Emerg Med. 2013;44(4):735-41.

227. Herrán-Monge R, Muriel-Bombín A, García-García MM, Merino-García PA, CítoresGonzález R, Fernández-Ratero JA, et al. Mortality reduction and long-term compliance with surviving sepsis campaign: a nationwide multicenter study. Shock. 2016;45(6):598-606.

228. Rhodes A, Phillips G, Beale R, Cecconi M, Chiche JD, De Backer D, et al. The Surviving Sepsis Campaign bundles and outcome: results from the International Multicentre Prevalence Study on Sepsis (the IMPreSS study). Intensive Care Med. 2015;41(9):1620-8.

229. Levy MM, Rhodes A, Phillips GS, Townsend SR, Schorr CA, Beale R, et al. Surviving Sepsis Campaign: association between performance metrics and outcomes in a 7.5-year study. Intensive Care Med. 2014;40(11):1623-33.

230. Jacob ST, Banura P, Baeten JM, Moore CC, Meya D, Nakiyingi L, et al. The impact of early monitored management on survival in hospitalized adult Ugandan patients with severe sepsis: a prospective intervention study*. Crit Care Med. 2012;40(7):2050-8.

231. Papali A, Eoin West T, Verceles AC, Augustin ME, Nathalie Colas L, Jean-Francois CH, et al. Treatment outcomes after implementation of an adapted WHO protocol for severe sepsis and septic shock in Haiti. J Crit Care. 2017;41:222-8.

232. Apisarnthanarak A, Thongphubeth K, Sirinvaravong S, Kitkangvan D, Yuekyen C, Warachan $\mathrm{B}$, et al. Effectiveness of multifaceted hospitalwide qualityimprovement programs featuring an intervention to removeunnecessary urinary catheters at a tertiary care center in Thailand. Infect Control Hosp Epidemiol. 2007;28(7):791-8.

233. Apisarnthanarak A, Thongphubeth K, Yuekyen C, Warren DK, Fraser VJ. Effectiveness of a catheter-associated bloodstream infection bundle in a Thai tertiary care center: a 3-year study. Am J Infect Control. 2010;38(6):449-55.

234. Djogovic D, Green R, Keyes R, Gray S, Stenstrom R, Sweet D, et al. Canadian Association of Emergency Physicians sepsis treatment checklist: optimizing sepsis care in Canadian emergency departments. CJEM. 2012;14(1):36-9.

235. Ballow SL, Kaups KL, Anderson S, Chang M. A standardized rapid sequence intubation protocolfacilitates airway management in critically injured patients. J Trauma Acute Care Surg. 2012;73(6):1401-5.

236. Vukoja M, Kashyap R, Gavrilovic S, Dong Y, Kilickaya O, Gajic O. Checklist for early recognition and treatment of acute illness: International collaboration to improve critical care practice. World J Crit Care Med. 2015;4(1):55-61.

237. Woodhouse D, Berg M, van der Putten J, Houtepen J. Will benchmarking ICUs improve outcome? Curr Opin Crit Care. 2009;15(5):450-5.

238. Rhodes A, Moreno RP, Azoulay E, Capuzzo M, Chiche JD, Eddleston J, et al. Prospectively defined indicators to improve the safety and quality of care for critically ill patients: a report from the Task Force on Safety and Quality of the European Society of Intensive Care Medicine (ESICM). Intensive Care Med. 2012;38(4):598-605.

239. Braun JP, Kumpf O, Deja M, Brinkmann A, Marx G, Bloos F, et al. The German quality indicators in intensive care medicine 2013-second edition. Ger Med Sci. 2013;11:Doc09.

240. Ray B, Samaddar DP, Todi SK, Ramakrishnan N, John G, Ramasubban S. Quality indicators for ICU: ISCCM guidelines for ICUs in India. Indian J Crit Care Med. 2009;13(4):173-206.

241. Swedish Intensive Care Registry. http://www.icuregswe.org/en/About-Intensive-Care/ registries/. Accessed 25 May 2017.

242. National Intensive Care Surveillance: a critical care clinical registry and bed availability system for Sri Lanka. http://www.nicslk.com/. Accessed 25 May 2017.

243. Malaysian Registry of Intensive Care. http://mric.org.my/Web/Page/index.aspx. Accessed 25 May 2017.

244. Wong A, Masterson G. Improving quality in intensive care unit practice through clinical audit. J Intensive Care Soc. 2015;16(1):5-8. 
245. Colvin JR, Peden C, editors. Raising the Standard: a compendium of audit recipes for continuous quality improvement in anaesthesia. Royal College of Anaesthetists; 2012. http:// www.rcoa.ac.uk/system/files/CSQ-ARB-2012_1.pdf.

246. Scales DC, Dainty K, Hales B, Pinto R, Fowler RA, Adhikari NK, et al. A multifaceted intervention for quality improvement in a network of intensive care units: a cluster randomized trial. JAMA. 2011;305(4):363-72.

247. Andrews B, Muchemwa L, Kelly P, Lakhi S, Heimburger DC, Bernard GR. Simplified severe sepsis protocol: a randomized controlled trial of modified early goal-directed therapy in Zambia. Crit Care Med. 2014;42(11):2315-24.

248. Maitland K, Kiguli S, Opoka RO, Engoru C, Olupot-Olupot P, Akech SO, et al. Mortality after fluid bolus in African children with severe infection. N Engl J Med. 2011;364(26):2483-95.

Open Access This chapter is licensed under the terms of the Creative Commons Attribution 4.0 International License (http://creativecommons.org/licenses/by/4.0/), which permits use, sharing, adaptation, distribution and reproduction in any medium or format, as long as you give appropriate credit to the original author(s) and the source, provide a link to the Creative Commons license and indicate if changes were made.

The images or other third party material in this chapter are included in the chapter's Creative Commons license, unless indicated otherwise in a credit line to the material. If material is not included in the chapter's Creative Commons license and your intended use is not permitted by statutory regulation or exceeds the permitted use, you will need to obtain permission directly from the copyright holder.

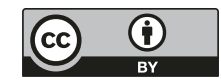

